\title{
Variability of Subantarctic Mode Water and Antarctic Intermediate Water in the Drake Passage during the Late-Twentieth and Early-Twenty-First Centuries
}

\author{
Alberto C. Naveira Garabato \\ National Oceanography Centre, Southampton, Southampton, United Kingdom \\ LOÏC JULLION \\ School of Environmental Sciences, University of East Anglia, Norwich, United Kingdom \\ DAVID P. STEVENS \\ School of Mathematics, University of East Anglia, Norwich, United Kingdom \\ KAREN J. HEYWOOD \\ School of Environmental Sciences, University of East Anglia, Norwich, United Kingdom \\ BRIAN A. KING \\ National Oceanography Centre, Southampton, Southampton, United Kingdom
}

(Manuscript received 9 May 2008, in final form 12 January 2009)

\begin{abstract}
A time series of the physical and biogeochemical properties of Subantarctic Mode Water (SAMW) and Antarctic Intermediate Water (AAIW) in the Drake Passage between 1969 and 2005 is constructed using 24 transects of measurements across the passage. Both water masses have experienced substantial variability on interannual to interdecadal time scales. SAMW is formed by winter overturning on the equatorward flank of the Antarctic Circumpolar Current (ACC) in and to the west of the Drake Passage. Its interannual variability is primarily driven by variations in wintertime air-sea turbulent heat fluxes and net evaporation modulated by the El Niño-Southern Oscillation (ENSO). Despite their spatial proximity, the AAIW in the Drake Passage has a very different source than that of the SAMW because it is ventilated by the northward subduction of Winter Water originating in the Bellingshausen Sea. Changes in AAIW are mainly forced by variability in Winter Water properties resulting from fluctuations in wintertime air-sea turbulent heat fluxes and spring sea ice melting, both of which are linked to predominantly ENSO-driven variations in the intensity of meridional winds to the west of the Antarctic Peninsula. A prominent exception to the prevalent modes of SAMW and AAIW formation occurred in 1998, when strong wind forcing associated with constructive interference between ENSO and the southern annular mode (SAM) triggered a transitory shift to an Ekmandominated mode of SAMW ventilation and a 1-2-yr shutdown of AAIW production.

The interdecadal evolutions of SAMW and AAIW in the Drake Passage are distinct and driven by different processes. SAMW warmed (by $\sim 0.3^{\circ} \mathrm{C}$ ) and salinified (by $\sim 0.04$ ) during the 1970 s and experienced the reverse trends between 1990 and 2005, when the coldest and freshest SAMW on record was observed. In contrast, AAIW underwent a net freshening (by $\sim 0.05$ ) between the 1970 s and the twenty-first century. Although the reversing changes in SAMW were chiefly forced by a $\sim 30$-yr oscillation in regional air-sea turbulent heat fluxes and precipitation associated with the interdecadal Pacific oscillation, with a SAMdriven intensification of the Ekman supply of Antarctic surface waters from the south contributing significantly too, the freshening of AAIW was linked to the extreme climate change that occurred to the west of the Antarctic Peninsula in recent decades. There, a freshening of the Winter Water ventilating AAIW was brought about by increased precipitation and a retreat of the winter sea ice edge, which were seemingly
\end{abstract}

Corresponding author address: Dr. Alberto C. Naveira Garabato, School of Ocean and Earth Science, National Oceanography Centre, Southampton SO14 3ZH, United Kingdom.

E-mail: acng@noc.soton.ac.uk

DOI: $10.1175 / 2009 J C L I 2621.1$ 
forced by an interdecadal trend in the SAM and regional positive feedbacks in the air-sea ice coupled climate system. All in all, these findings highlight the role of the major modes of Southern Hemisphere climate variability in driving the evolution of SAMW and AAIW in the Drake Passage region and the wider South Atlantic and suggest that these modes may have contributed significantly to the hemispheric-scale changes undergone by those waters in recent decades.

\section{Introduction}

The Southern Ocean plays a pivotal role in World Ocean circulation and climate. The absence of continents in the Drake Passage latitude band permits the occurrence of the Antarctic Circumpolar Current (ACC), which acts as the major conduit for water masses and oceanic climate signals to propagate around the globe. Coupled to the quasi-zonal flow of the ACC by subtle dynamics, a meridional overturning circulation exists in the Southern Ocean that implicates the vigorous vertical transport and transformation of several globally significant water masses (for reviews, see Rintoul et al. 2001; Olbers et al. 2004). The most voluminous among these is the Circumpolar Deep Water (CDW), which originates primarily from North Atlantic Deep Water and experiences net poleward transport and upwelling in the Southern Ocean. Upon reaching the upper layers of the ACC, Circumpolar Deep Water is transformed into equatorward-flowing Antarctic Surface Water (AASW), which subducts near the Polar Front (PF) and thereby contributes to the formation of the Antarctic Intermediate Water (AAIW) emerging to the north of the Subantarctic Front (SAF; see Santoso and England 2004 and references therein). Overlying AAIW north of this front, Subantarctic Mode Water (SAMW) is produced by the winter deepening of the upper-ocean mixed layer in several areas of the south Indian and South Pacific Oceans (e.g., Aoki et al. 2007), a process that has also been argued to play an important part in AAIW formation (McCartney 1977; see also Talley 1996). SAMW and AAIW are exported northward to the southern subtropical gyres and beyond, thus ventilating the permanent pycnocline and mediating the storage of climatic anomalies in those regions.

Changes in Southern Ocean mode and intermediate water masses are a recurrent outstanding feature in model projections of present and future climate change (e.g., Stark et al. 2006; Fyfe et al. 2007). However, the relative paucity of observations in the region poses a serious challenge to the detection of variability in these waters. Using a set of temperature measurements obtained over eight decades (1930s-2000s), Gille (2002, 2008) reported an extensive warming of the upper kilometer of the water column around the northern edge of the ACC by $0.17^{\circ} \pm$ $0.06^{\circ} \mathrm{C}$ between the $1950 \mathrm{~s}$ and the $1980 \mathrm{~s}$, which doubled the global-mean trend for that depth range and continued at a lesser rate into the 2000s. Possibly related to this widespread change, instances of regional variability in mode and intermediate water masses have been documented by several studies. These reveal that the layer between 1000 and 2000 dbar (containing a large fraction of AAIW) of the subtropical Atlantic warmed by $\sim 0.3^{\circ} \mathrm{C}$ on pressure surfaces between the 1920s and the 1990s (Arbic and Owens 2001) and that SAMW and AAIW in the subtropical gyre of the South Atlantic freshened by $\sim 0.02$ on density surfaces between the 1950s-60s and the 1980s-90s (Curry et al. 2003). Concurrently, cooling (by approximately $0.3^{\circ}-0.5^{\circ} \mathrm{C}$ ) and freshening (by 0.02-0.1) of SAMW and AAIW occurred on density surfaces between the 1960s/70s and the 1980s/90s across the Indian and Pacific sectors of the Southern Ocean (Bindoff and Church 1992; Johnson and Orsi 1997; Wong et al. 1999, 2001; Bindoff and McDougall 2000; Aoki et al. 2005). Although this trend persisted in the lower pycnocline of the south Indian Ocean until the turn of the twenty-first century, a reversal occurred in the upper pycnocline during the 1990s (Bryden et al. 2003; McDonagh et al. 2005). In the South Pacific Ocean, this decade saw a continuation of the cooling and freshening trend (on density surfaces) in SAMW and a switch to a warming and salinifying tendency in AAIW (Schneider et al. 2005).

The literature on SAMW and AAIW variability was recently reviewed and synthesized by the Intergovernmental Panel on Climate Change (IPCC) in its Fourth Assessment Report (Bindoff et al. 2007), which indicated that the observed changes form part of a globalscale pattern of decadal warming and freshening (salinification) of mode and intermediate waters of subpolar (subtropical) origin. As pointed out in the report and in a number of studies cited therein, this pattern is a plausible major feature of the oceanic response to the global atmospheric warming and acceleration of the atmospheric hydrological cycle that are thought to have occurred in recent decades and that are consistent with model projections of climate change in rising greenhouse gas scenarios.

Here, we examine the interannual to interdecadal variability over the last four decades in the SAMW and AAIW conveyed by the ACC through Drake Passage 
TABLE 1. Drake Passage sections examined in this study, listed alongside their nominal location, the vessel with which they were conducted, the dates of their occupation, and the measured parameters of relevance to this work with the corresponding sampling methods.

\begin{tabular}{|c|c|c|c|}
\hline Nominal section location & Vessel & Dates of occupation & Measured parameters (sampling method) \\
\hline SR1 & Thomas Washington & 20-27 Jan 1969 & $p, \theta, S, \mathrm{O}_{2}, \mathrm{Si}$ (bottle) \\
\hline SR1W & Hudson & 5-15 Feb 1970 & $p, \theta, S, \mathrm{O}_{2}, \mathrm{Si}$ (bottle) \\
\hline SR1 & Melville & 27 Feb-7 Mar 1975 & $p, \theta, S, \mathrm{O}_{2}, \mathrm{Si}$ (bottle) \\
\hline SR1 & Melville & 16-22 Mar 1975 & $p, \theta, S, \mathrm{O}_{2}, \mathrm{Si}$ (bottle) \\
\hline SR1 & Thompson & 26 Feb-3 Mar 1976 & $p, \theta, S, \mathrm{O}_{2}, \mathrm{Si}$ (bottle) \\
\hline SR1 & Melville & 19 Jan-13 Feb 1977 & $p, \theta, S, \mathrm{O}_{2}, \mathrm{Si}$ (bottle) \\
\hline SR1 & Yelcho & 15-20 Apr 1979 & $p, \theta, S, \mathrm{O}_{2}, \mathrm{Si}$ (bottle) \\
\hline SR1 & Atlantis & 19 Jan-13 Feb 1980 & $p, \theta, S, \mathrm{O}_{2}, \mathrm{Si}$ (bottle) \\
\hline SR1W & Meteor & 24 Jan-1 Feb 1990 & $p, \theta, S$ (CTD), $\mathrm{O}_{2}, \mathrm{Si}$ (bottle) \\
\hline SR1b & James Clark Ross & 21-26 Nov 1993 & $p, \theta, S(\mathrm{CTD})$ \\
\hline SR1b & James Clark Ross & 15-21 Nov 1994 & $p, \theta, S(\mathrm{CTD})$ \\
\hline SR1b & Hespérides & 15-19 Feb 1996 & $p, \theta, S(\mathrm{CTD})$ \\
\hline SR1b & James Clark Ross & 15-20 Nov 1996 & $p, \theta, S(\mathrm{CTD})$ \\
\hline SR1b & James Clark Ross & 29 Dec 1997-7 Jan 1998 & $p, \theta, S$ (CTD), $\mathrm{O}_{2}, \mathrm{Si}$ (bottle) \\
\hline SR1b & Hespérides & 13-18 Feb 1998 & $p, \theta, S(\mathrm{CTD})$ \\
\hline SR1b & Hespérides & 8-14 Dec 1998 & $p, \theta, S(\mathrm{CTD})$ \\
\hline SR1W & James Clark Ross & 18-26 Mar 1999 & $p, \theta, S$ (CTD), $\mathrm{O}_{2}, \mathrm{Si}$ (bottle) \\
\hline SR1b & James Clark Ross & 12-17 Feb 2000 & $p, \theta, S(\mathrm{CTD})$ \\
\hline SR1b & James Clark Ross & $22-28$ Nov 2000 & $p, \theta, S(\mathrm{CTD})$ \\
\hline SR1b & James Clark Ross & 20-26 Nov 2001 & $p, \theta, S(\mathrm{CTD})$ \\
\hline SR1b & James Clark Ross & 27 Dec 2002-1 Jan 2003 & $p, \theta, S(\mathrm{CTD})$ \\
\hline SR1b & James Clark Ross & 11-15 Dec 2003 & $p, \theta, S(\mathrm{CTD})$ \\
\hline SR1b & James Clark Ross & 2-8 Dec 2004 & $p, \theta, S(\mathrm{CTD})$ \\
\hline SR1b & James Clark Ross & 7-12 Dec 2005 & $p, \theta, S(\mathrm{CTD})$ \\
\hline
\end{tabular}

with a twofold goal. First, we assess the extent to which the Southern Ocean mode and intermediate water mass changes stemming from previous studies that focused on the subtropical oceans with regard to the Drake Passage chokepoint, a site of great significance in the interocean exchange of those waters. Second, we aim to exploit the comparatively high density of high-quality measurements in the area-perhaps unmatched around the ACC - to investigate the timing and causes of the observed variability with unprecedented clarity.

\section{Data and methods}

\section{a. Hydrographic and tracer measurements}

We have compiled 24 meridional sections of hydrographic (and, in 11 of them, various biogeochemical tracer) measurements across the Drake Passage, obtained between 1969 and 2005 (Table 1). The initial eight transects were occupied by U.S., Canadian, and Chilean research vessels in 1969-80, many as part of the International Southern Ocean Studies. Data from these sections were acquired from the National Oceanographic Data Center World Ocean Database (available online at http://www.nodc.noaa.gov). The remaining 16 transects were conducted by British, German, and Spanish vessels between 1990 and 2005 with nearly annual periodicity and under the auspices of the World
Ocean Circulation Experiment (WOCE) and the postWOCE repeat hydrography program. Data from these sections were obtained from the WOCE Hydrographic Program Office (available online at http://whpo.ucsd. edu) and for the latest, not-yet released sections, from the relevant National Oceanography Centre, Southampton, data archives. All sections were occupied in austral spring, summer, and early autumn and lie broadly along one of three different tracks labeled, from west to east: SR1W, SR1 and SR1b (Fig. 1). The initial eight transects (1969-80) collected bottle measurements with a vertical resolution that decreased with depth (from $10-20 \mathrm{~m}$ in the upper ocean to as much as $250 \mathrm{~m}$ in the abyss), whereas subsequent sections obtained CTD measurements with 1- or 2-dbar resolution. The section dataset was extended with 421 Argo profiles obtained in the area bounded by (or within $100 \mathrm{~km}$ away from) the transects between 2002 and 2005 (Fig. 1), with a variable vertical resolution ranging from $\sim 10 \mathrm{~m}$ near the surface to $\sim 70 \mathrm{~m}$ at depth. Argo profile data were made available by the International Argo Project (available online at http://www.argo.ucsd.edu). This eclectic Drake Passage dataset was supplemented with the WOCE P19 section, occupied in early 1993, and 417 Argo profiles, conducted in the southeast Pacific between 2002 and 2005 (Fig. 1). Our analysis of uncertainties in the measurements is outlined in the appendix. 


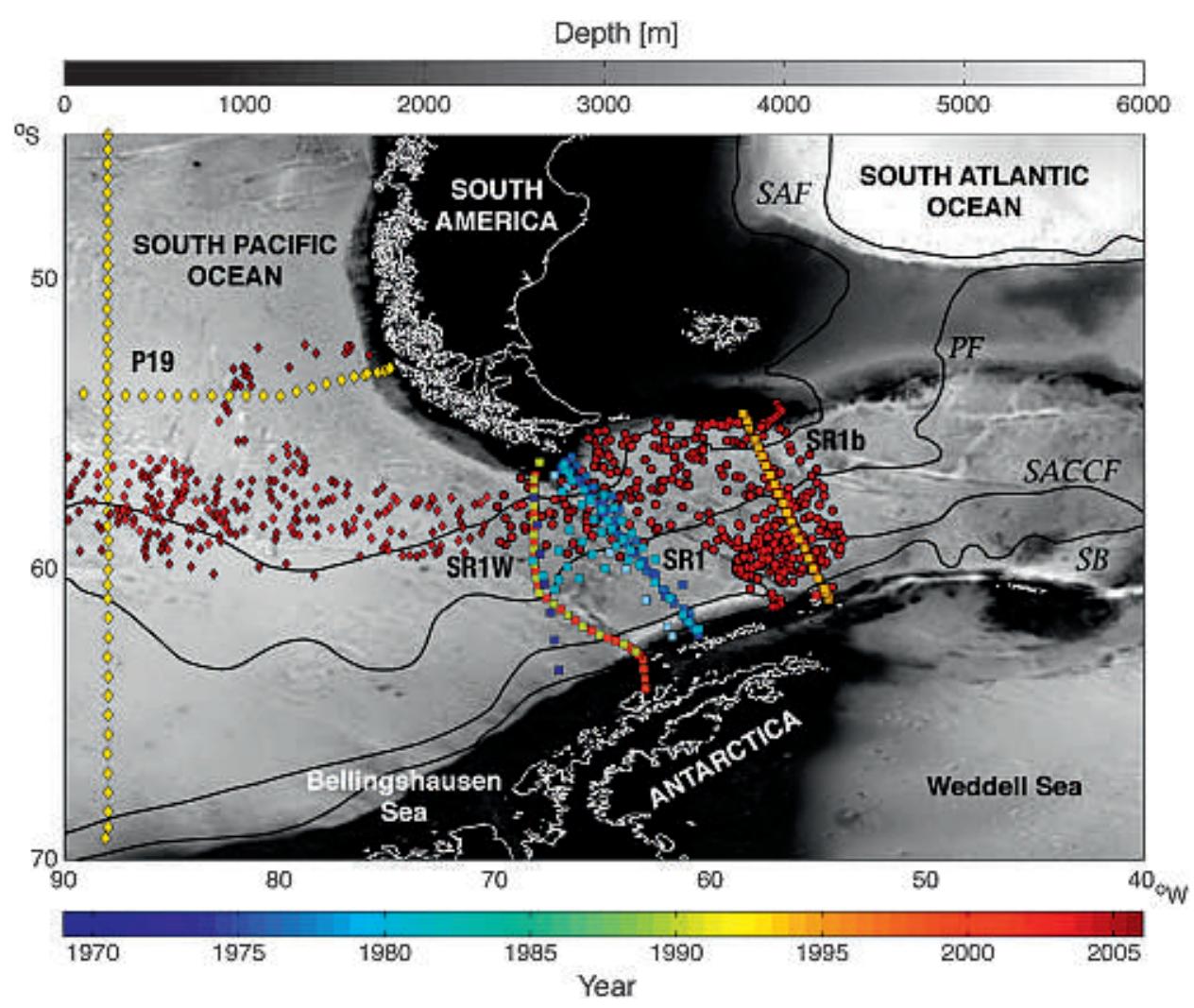

FIG. 1. Bathymetry of the southeast Pacific-Drake Passage region (in gray), with locations of hydrographic profiles colored by the time of sampling. CTD station (Argo profile) positions are marked by squares (dark red circles) in the Drake Passage and by large yellow diamonds (small dark-red diamonds) in the southeast Pacific. Hydrographic transects and significant geographical features are labeled.

To synthesize the variability in mode and intermediate water mass properties present in our large dataset, we compute the means of different fragments of the sections (and sets of Argo profiles) defined on the basis of the geopotential height anomaly at 500 dbar relative to $1500 \mathrm{dbar}(\varphi)$ as a horizontal coordinate in the crosspassage direction with either pressure $p$ or the neutral density $\gamma^{n}$ of Jackett and McDougall (1997) as a vertical coordinate. In the meandering ACC, $\varphi$ provides an accurate characterization of cross-stream position and is thus preferable to latitude. Further, it displays a tight correspondence with the ACC frontal anatomy determined using the criteria of Orsi et al. (1995). Our results are insensitive to the choice of pressure levels in the definition of $\varphi$. The use of a dual vertical coordinate facilitates interpretation of the causes of the observed variability (Bindoff and McDougall 1994), but in this article we only display means on isopycnal surfaces for succinctness. Prior to calculating means, the station data are interpolated onto two sets of standard levels: one for the vertical coordinate ( $p$ or $\gamma^{n}$ ) and another for $\varphi$. The averaging process in the $\varphi$ coordinate system approximates the calculation of a transport-weighted mean property value, because it emphasizes the sectors of the ACC with large baroclinic transport. Figure 2 shows an illustrative section of potential temperature $(\theta)$, salinity $(S)$, dissolved oxygen $\left(\mathrm{O}_{2}\right)$, and dissolved silicate (Si) across the Drake Passage, with $\gamma^{n}$ surfaces superimposed as contours and $\varphi$ and the ACC frontal positions indicated in the top of the figure. The section fragments at the core of our analysis are delimited by white lines and will be defined in section 3 on the basis of particular $\varphi$ and $\gamma^{n}$ ranges.

\section{b. Ancillary observations and indices}

To investigate the causes of the measured SAMW and AAIW changes, we examine a range of ancillary datasets describing the state of the Southern Hemisphere coupled air-sea-ice climate system. We characterize the major modes of hemispheric climate variability with the monthly bivariate El Niño-Southern Oscillation (ENSO) time series index (Smith and Sardeshmukh 2000; available online at http://www.cdc.noaa.gov/people/cathy. smith/best/); the monthly southern annular mode (SAM) index of Marshall (2003; available online at http://www. nerc-bas.ac.uk/icd/gjma/sam.html); and the interdecadal 


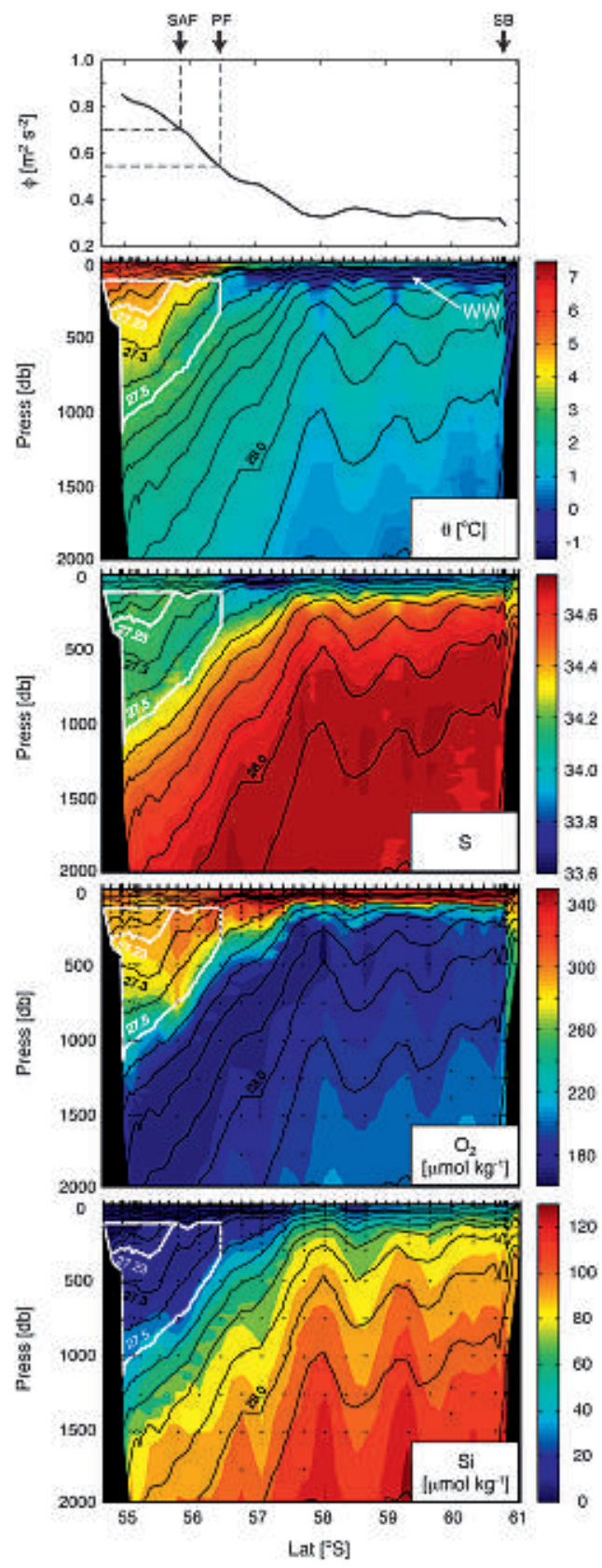

FIG. 2. Distributions of (top)-(bottom) $\varphi, \theta, S, \mathrm{O}_{2}$, and $\mathrm{Si}$ (in color) across Drake Passage during the WOCE SR1b transect in December 1997-January 1998 (Table 1). Neutral density $\gamma^{n}$ contours are shown in black and station positions denoted by tick marks on the upper axis of the lower four panels. The SAF, PF, and southern boundary (SB) of the ACC are marked by arrows at the top of the upper panel and the $\varphi$ coordinates of the first two fronts are indicated by dashed lines. The cross-sectional areas of SAMW and AAIW defined in our analysis (see section 3 ) are delimited by the closed white lines in the lower four panels. The $\theta$ minimum of Winter Water is labeled as WW in the second panel.
Pacific oscillation (IPO) index of Parker et al. (2007), defined on the basis of the second covariance empirical orthogonal function of low-pass-filtered global sea surface temperature (SST). Further, we examine monthly time series of wind stress, air-sea heat flux, and net precipitation from the National Centers for Environmental Prediction-National Center for Atmospheric Research (NCEP-NCAR) reanalysis (Kalnay et al. 1996; available online at http://www.cdc.noaa.gov/cde/ reanalysis/reanalysis.shtml) and the 40-yr European Centre for Medium-Range Weather Forecasts ReAnalysis (ERA-40) project (available online at http:// www.ecmwf.int/products/data/archive/descriptions/e4/ index.html). Although we found no significant qualitative differences in examining one or the other product, we follow the strategy of presenting results from the more up-to-date NCEP-NCAR reanalysis when time series length is important for a given piece of analysis, and from the somewhat better-performing ERA-40 product when greater accuracy is preferable. We also analyze optimally interpolated SST fields based on in situ and satellite observations (Reynolds et al. 2002; available online at http://www.cdc.noaa.gov/cdc/ data.noaa.oisst.v2.html) and sea ice concentration data derived from the Nimbus-7 Scanning Multichannel Microwave Radiometer and Defense Meteorological Satellite Program Special Sensor Microwave Imager passive microwave measurements (available online from the National Snow and Ice Data Center at http:// nsidc.org/). Anomalies of atmospheric fields, SST, and sea ice concentration are calculated by subtracting the local time-mean annual cycle at each point in space.

\section{SAMW and AAIW variability}

The clearest signal of interdecadal variability is evident in SAMW $\left(0.70<\varphi<0.85 \mathrm{~m}^{2} \mathrm{~s}^{-2} ; 26.80<\gamma^{n}<\right.$ $27.23 \mathrm{~kg} \mathrm{~m}^{-3}$ ) north of the SAF (Fig. 3). (Note that nearly all Drake Passage sections display a single significant mode of SAMW and that measurements in the uppermost 120 dbar are disregarded in averaging so as to exclude short-term variability in the upper ocean.) There, $\theta$ and $S$ increased on density surfaces by $0.2^{\circ}-0.4^{\circ} \mathrm{C}$ and $\sim 0.05 \mathrm{psu}$, respectively, during the 1970s. This trend must have peaked during the 1980 s, when no sections were occupied, and then reversed more than fully between the early 1990s and 2005, at which point the coldest and freshest (on isopycnals) SAMW was encountered. We observe no statistically significant decadal change in the mean pressure or mean isopycnal potential vorticity magnitude $\left(\mathrm{PV} ; \mathrm{PV}=f \rho^{-1} \partial \rho / \partial z\right.$, where $f$ is the inertial frequency, $\rho$ is potential density, and $z$ is height) of SAMW, although an increase in the 


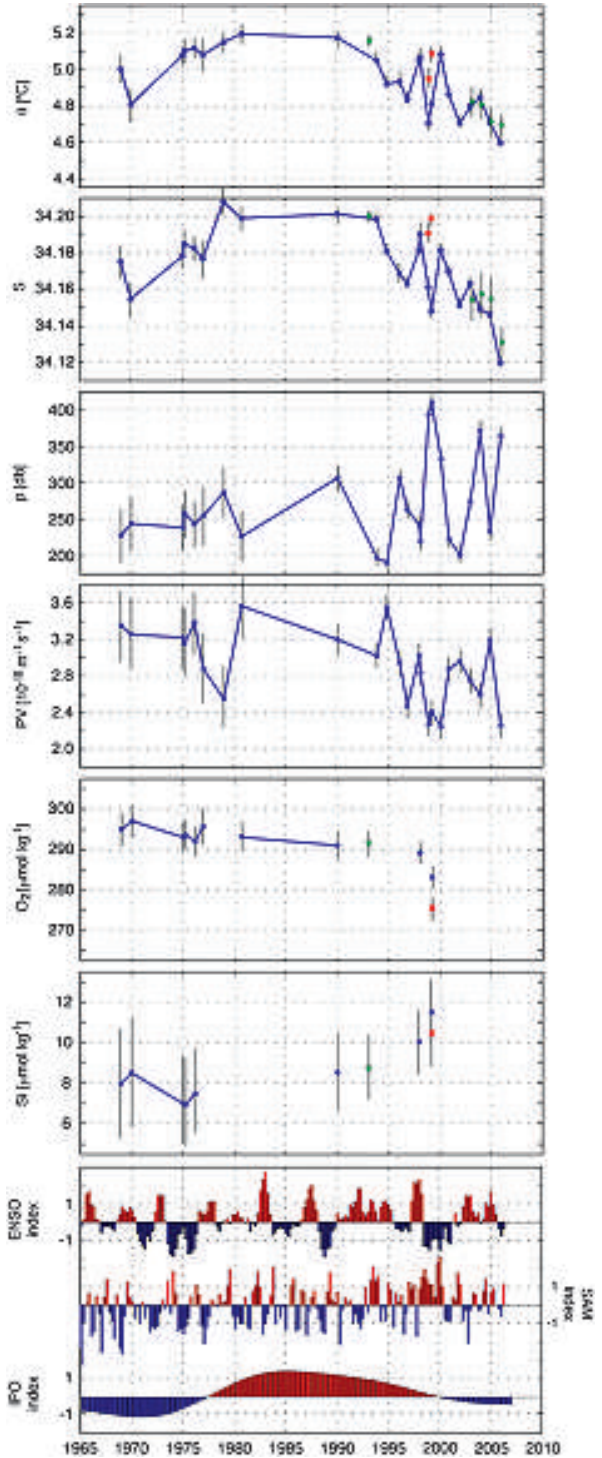

FIG. 3. (top)-(sixth) Time series of $\theta, S, p, \mathrm{PV}, \mathrm{O}_{2}$, and $\mathrm{Si}$ of SAMW, as defined in section 3 and Fig. 2. Here, $\theta, S, \mathrm{PV}, \mathrm{O}_{2}$, and $\mathrm{Si}$ are layer-mean values, whereas $p$ is the average value at the lower boundary of SAMW. Blue circles and red squares denote measurements in the Drake Passage, with gray lines indicating error bars. In 1998/99, two SAMW modes were present: at this time, the blue circles represent the volumetrically dominant southern mode and the red squares represent the less abundant northern mode. Green diamonds display observations in the southeast Pacific obtained by the WOCE P19 section in 1993 and Argo floats in 2002-05 (Fig. 1). The latter are extracted in the $0.54<\varphi<0.85$ $\mathrm{m}^{2} \mathrm{~s}^{-2}$ range to the south of $52^{\circ} \mathrm{S}$. To minimize errors arising from undersampling of cross-stream thermohaline gradients by Argo floats, season-mean $\theta$ and $S$ values are computed in two steps: first, for each density surface and $\varphi$ "streamline" sampled by a float, the $\theta$ and $S$ anomalies relative to the Drake Passage time-mean $\theta$ and $S$ values at that isopycnal and that streamline are calculated; second, the means of those anomalies are added to the time-mean $\theta$ and $S$ values of the entire SAMW layer in the Drake Passage. (bottom) Time series of indices of three major modes of Southern Hemisphere climate variability: ENSO, SAM, and IPO. frequency of interannual deepening and thickening events after the mid-1990s is suggested. The $\mathrm{O}_{2}$ and $\mathrm{Si}$ of the SAMW layer display no appreciable variability throughout the available record except for one instance of significantly lower $\mathrm{O}_{2}$ and higher $\mathrm{Si}$ concentrations in early 1999. In section 4, we will argue that these anomalous $\mathrm{O}_{2}$ and $\mathrm{Si}$ values likely correspond to an interannual-scale event rather than to interdecadal change.

The interdecadal variability in SAMW is frequently punctuated by interannual $\theta, S, p$, and PV changes of up to $0.4^{\circ} \mathrm{C}, 0.04, \sim 100 \mathrm{dbar}$, and $8 \times 10^{-11} \mathrm{~m}^{-1} \mathrm{~s}^{-1}$, respectively, that do not mask longer-period signals (Fig. 3). The most prominent of the observed interannual changes was a cool, fresh, high- $p$, and low-PV anomaly in 1998/99. This was the only occasion in which more than one significant mode of SAMW was measured and coincided with the only significant (negative) $\mathrm{O}_{2}$ and (positive) $\mathrm{Si}$ anomalies on record. On these interannual time scales, there is a statistically significant correspondence between the positive (negative) $\theta$ and $S$ anomalies and the mean shoaling and thinning (deepening and thickening) of the SAMW layer. A major exception to this general relationship occurred in the warmer, more saline mode of SAMW of 1998/99, which exhibited positive $\theta$ and $S$ anomalies in conjunction with mean deepening and thickening.

As in the case of SAMW, AAIW $(0.54<\varphi<0.70$ $\mathrm{m}^{2} \mathrm{~s}^{-2} ; 27.23<\gamma^{n}<27.50 \mathrm{~kg} \mathrm{~m}^{-3}$ ) north of the PF displays a significant interdecadal change too (Fig. 4), although this is rather subtle. It consists of a net freshening (by $\sim 0.02$ ) of the water mass between the 1970s and the early-twenty-first century, as evidenced by the fact that, in 6 out of the 10 summers between 1996/97 and 2005/06, AAIW was significantly fresher than in all available observations prior to that period. This decadal variation is partially concealed by a pronounced interannual salinification event in 1998/99. Other than salinity, no significant interdecadal variability is detected in the properties of AAIW.

The interannual variability of AAIW is dominated by fluctuations of $1-3$-yr duration and up to $0.6^{\circ} \mathrm{C}(\theta), 0.07$ $(S), 100 \mathrm{dbar}(p)$, and $1.5 \times 10^{-11} \mathrm{~m}^{-1} \mathrm{~s}^{-1}(\mathrm{PV})$. The clearest expression of these changes is the multiannual warm, saline, deepening, and thinning event centered around 1998/99. This was the only instance in the entire record in which significant (negative) $\mathrm{O}_{2}$ and (positive) $\mathrm{Si}$ anomalies were observed. The association between the signs of the anomalies in the physical properties apparent in the 1998/99 event is characteristic of the interannual variability of AAIW in general: positive (negative) $\theta$ and $S$ anomalies on isopycnals occur in synchrony with net deepening and thinning (shoaling and thickening) of the AAIW layer. 

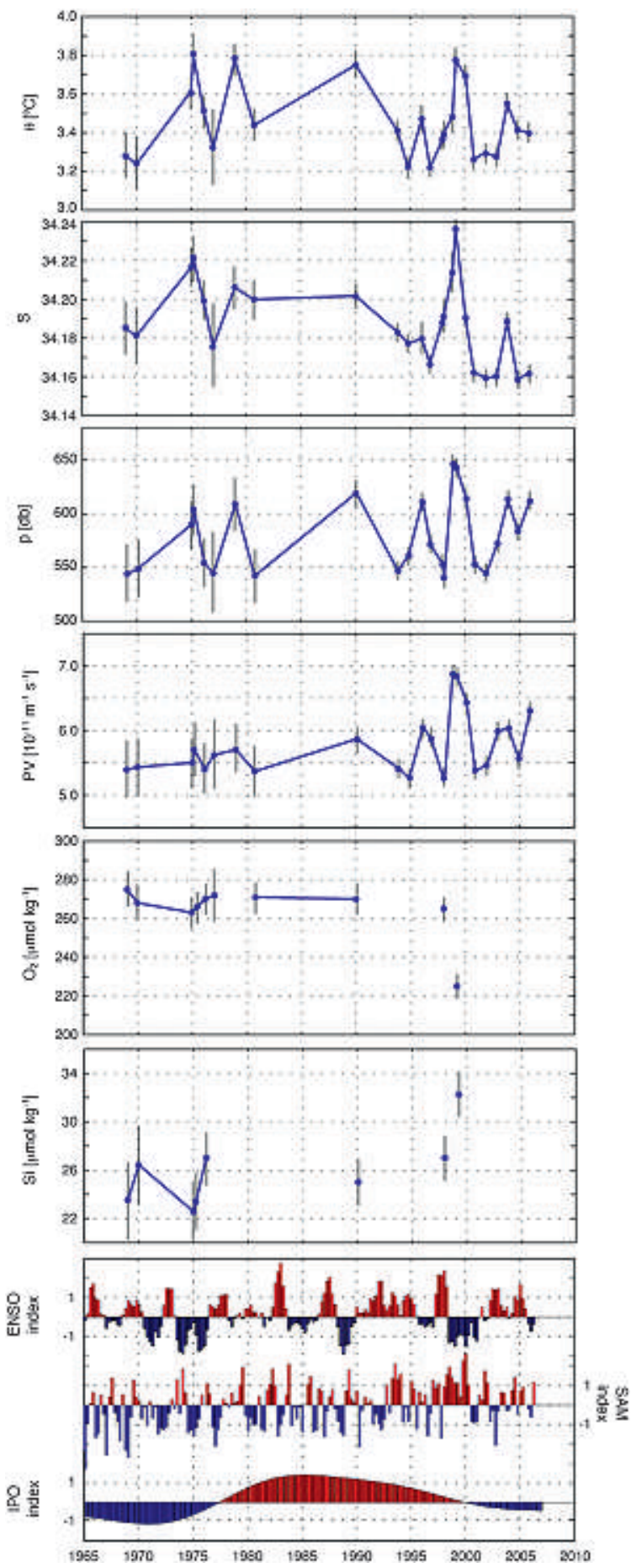

FIG. 4. (top)-(sixth) Time series of layer-mean $\theta, S, p, \mathrm{PV}, \mathrm{O}_{2}$, and $\mathrm{Si}$ of AAIW, as defined in section 3 and Fig. 2. Blue circles denote measurements in the Drake Passage, with gray lines indicating error bars. (bottom) Time series of indices of three major modes of Southern Hemisphere climate variability: ENSO, the SAM, and the IPO.

\section{Discussion}

In this section, we consider the nature and drivers of the observed variability in SAMW and AAIW properties. The discussion is organized in terms of the characteristic period of the variability and each water mass type.

\section{a. Interannual variability}

\section{1) Subantarctic Mode Water}

The interannual variability observed in SAMW properties is consistent with the classical notion that the water mass is formed by winter convection on the ACC equatorward flank (McCartney 1977). Thus, on these time scales, the SAMW layer is generally colder when it is deeper and less stratified, suggesting that strong winter heat loss is implicated in its formation. The region of the southeast Pacific immediately upstream of the Drake Passage has been identified as a key SAMW formation site, as evidenced by the occurrence of very deep $(>500 \mathrm{~m})$ winter mixed layers containing the coldest, freshest, and densest variety of SAMW found around Antarctica (Aoki et al. 2007). That the SAMW flowing through the Drake Passage originates in neighboring areas of the southeast Pacific and the passage itself, experiencing only minimal modification in transit, can be demonstrated by comparing the properties of SAMW observed in the Drake Passage in spring and summer with the characteristics of SAMW formed in the southeast Pacific during the preceding winter. Figure 3 shows that in the summer of 1992/93, the mode of SAMW encountered by the WOCE P19 section west of $80^{\circ} \mathrm{W}$ was almost identical to that observed in the passage during the early 1990s. This correspondence appears to hold between the SAMW measured by Argo floats in the southeast Pacific during the springs and summers of 2002/03-2005/06 and the SAMW observed in the Drake Passage in the same seasons and years. On the whole, these observations indicate that the SAMW found in the passage is formed nearby in the southeast Pacific-Drake Passage region, from where it reaches the passage's eastern edge in considerably less than one year (see also Piola and Gordon 1989). It follows that the variability of SAMW properties in the Drake Passage must reflect changes in newly formed SAMW across the neighboring region to the west.

This assertion is corroborated by the statistically significant correlation that exists between the potential temperature of SAMW in the Drake Passage and the SST of the southeast Pacific-Drake Passage region in the preceding winter during 1990-2005. As illustrated in Fig. 5, correlations in excess of 0.5 , significant at the $95 \%$ level, occur in a large area extending over $2500 \mathrm{~km}$ 


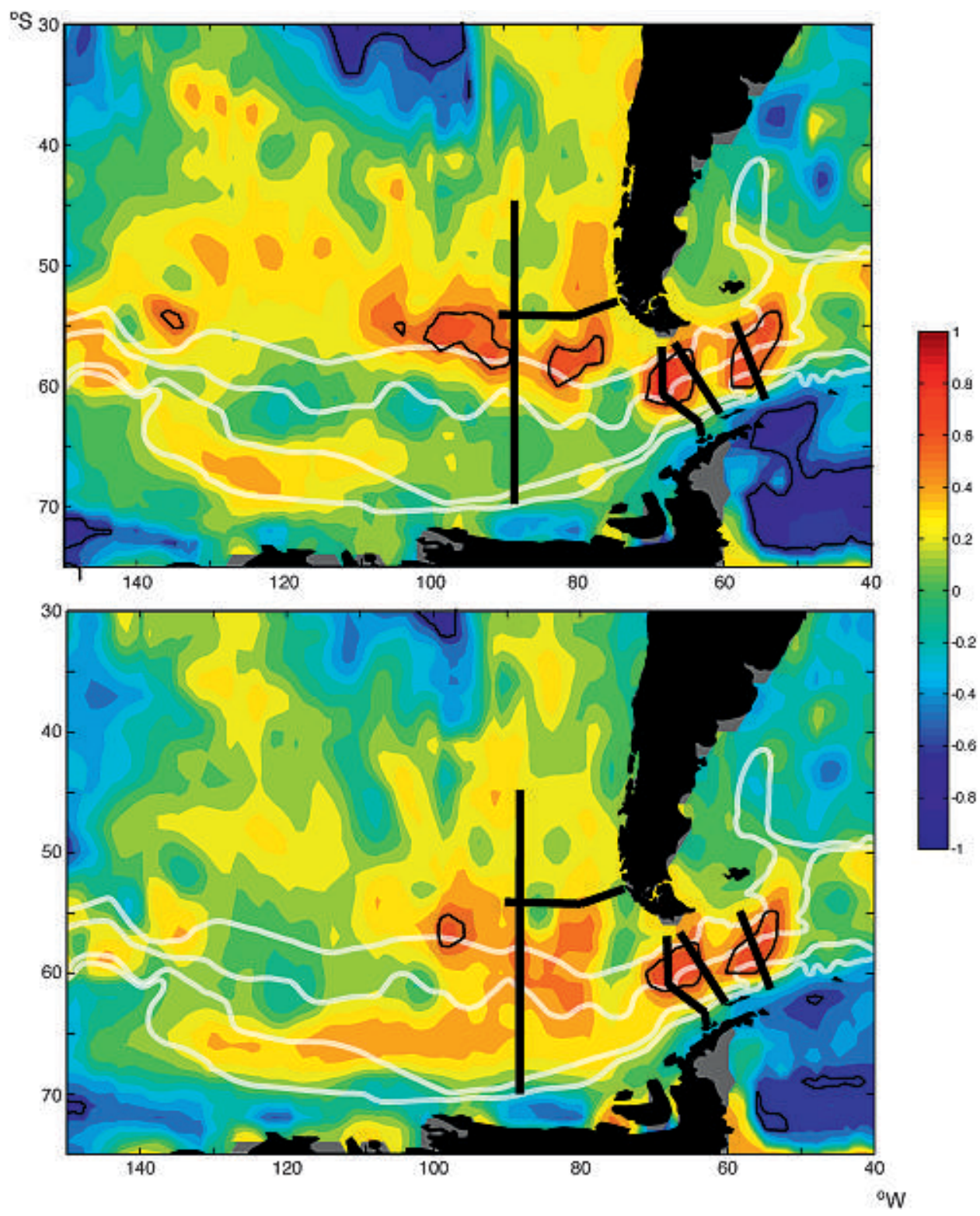

FIG. 5. Maps of the correlation between year-to-year changes in the spring-summer $\theta$ of SAMW in the Drake Passage and interannual variations in the preceding winter-mean SST (with winter defined as JulySeptember). Correlations are shown corresponding to time series including either the (top) northern or (bottom) southern SAMW mode in 1998/99; $95 \%$ significance is denoted by the black contours. Climatological frontal positions and section locations (Fig. 1) are shown by thick white and black lines, respectively.

zonally to the west of $\sim 55^{\circ} \mathrm{W}$ and around $500 \mathrm{~km}$ meridionally. ${ }^{1}$ This region is bounded to the south by the

\footnotetext{
${ }^{1}$ Note that statistically significant correlations also occur in several regions farther afield. These mirror large-scale structures in the dominant modes of Southern Hemispheric atmospheric variability (see below) and thus do not necessarily indicate the existence of a physical link to the SAMW in the Drake Passage over the subannual time scale of interest.
}

SAF in the southeast Pacific and straddles the SAF and PF in the Drake Passage. It is likely that the forcing mechanisms driving SST variability in this broad area are also responsible for the observed changes in the SAMW flowing through the passage. The variations in SAMW salinity seen in Fig. 3 do not result exclusively from examining property changes on isopycnals in the presence of potential temperature variability but genuinely reflect changes in the salinity of the regional winter 
mixed layer. This is demonstrated in Fig. 6, which shows the potential temperature, salinity, and neutral density of the subsurface $S$ maximum that marks the base of the winter mixed layer. It is apparent that $\theta$ and $S$ at the base of the SAMW vary concurrently on interannual periods, exhibiting a correlation of 0.4 that is significant at the $90 \%$ level. This positive correlation implies that $\theta$ and $S$ tend to vary in a density-compensating manner, with $\theta$ variations being the main contributor to interannual density fluctuations. On these time scales, years in which the winter mixed layer penetrates to an anomalously dense horizon regularly correspond with the occurrence of unusually cold, fresh, deep, and low-PV modes of SAMW (cf. Fig. 3).

The drivers of interannual changes in SAMW can be readily identified by calculating lagged cross correlations between a time series (1982-2007) of the monthly mean SST averaged over the SAMW formation region in the southeast Pacific-Drake Passage (defined approximately by the $95 \%$ significance contour in Fig. 5) and monthly mean indices of ENSO and the SAM, the two major modes of Southern Hemisphere climate variability on interannual time scales (Fig. 3, bottom). As shown in Fig. 7, the highest significant correlations (0.48) are obtained with the ENSO index at a lag of 4-6 months, with a less prominent peak (correlation of 0.28 ) at a longer lag of $\sim 19$ months. The significance of these peaks is notable, given that the extratropical atmosphere is known to exhibit rather distinct responses to different El Niño or La Niña events (Turner 2004). Correlations with the SAM index are somewhat lower and display two marginally significant peaks of $\sim 0.2$ at lags of 1-6 months and $\sim 22$ months. Positive (negative) SST anomalies are associated with El Niño-positive ENSO index (La Niña-negative ENSO index) events and a weakening of the polar vortex and decreased SAM index (an intensification of the polar vortex and increased SAM index). A linear regression of the SST time series against the ENSO and SAM indices, each with its aforementioned two lags, reveals that the reconstructed SST can explain $38 \%$ of the variance in the original SST time series, with ENSO and SAM explaining $35 \%$ and $6 \%$ individually (Fig. 8 ). Therefore, ENSO is a major driver of SST variability in the SAMW formation region of interest, and the SAM also exerts an appreciable influence. As illustrated by Fig. 8, this is true for interannual changes in winter-mean SST (and therefore SAMW potential temperature) as well as for monthly SST variability.

The double-peak structure of the lagged correlations of SST in the SAMW formation area with each of the two climate indices above reflects a genuine duality in the way ENSO and the SAM force the region. In the case of ENSO, the 4-6-month peak results from a direct atmospheric teleconnection between the equatorial and southeast Pacific, following a climatological Rossby wave train known as the Pacific-South American pattern (Turner 2004). This atmospheric wave train is also responsible for rapidly conveying ENSO signals to the western and central South Pacific, where very large SST anomalies are induced (Verdy et al. 2006). These anomalies are then advected eastward by the ACC and reach Drake Passage after $\sim 2$ yr (Meredith et al. 2008), thereby giving rise to the observed ENSO forcing of SST variability in the southeast Pacific with a $\sim 19$-month lag. In regard to the SAM, the 1-6-month lag reflects the near-local response of SST to fluctuations in the circumpolar westerly winds. The $\sim 22$-month lag is associated with the oceanic advection of strong SST anomalies induced by the SAM in the central South Pacific, which tends to result in an amplification of locally forced anomalies in the Drake Passage region (Verdy et al. 2006).

Whereas both the ENSO and SAM forcings of SST variability around the Southern Ocean generally implicate significant air-sea turbulent heat flux and winddriven Ekman components, Verdy et al. (2006) show that the former term is the dominant local driver of SST changes in the SAMW formation region of the southeast Pacific-Drake Passage (their Fig. 6). Accounting for the observed year-to-year $\theta$ variations $\left(\theta_{\text {anom }}\right)$ in SAMW requires a winter-mean air-sea turbulent heat flux anomaly of $Q_{\text {anom }}=\rho_{0} c_{p} h_{m} \theta_{\text {anom }} \Delta t^{-1}$, where $\rho_{0}$ is a reference density, $c_{p}$ is the specific heat capacity of seawater, $h_{m}$ is the depth of the winter mixed layer, and $\Delta t$ is the length of the winter season (e.g., Rintoul and England 2002). Using $\rho_{0}=1027 \mathrm{~kg} \mathrm{~m}^{-3}, c_{p}=3986$ $\mathrm{J} \mathrm{kg}^{-1} \mathrm{~K}^{-1}, h_{m} \approx 400 \mathrm{~m}$ (the characteristic depth of the remnant winter mixed layer observed in the northern Drake Passage), $\theta_{\text {anom }} \approx 0.2^{\circ} \mathrm{C}$ (a typical upper-bound $\theta$ change in SAMW; see Fig. 3), and $\Delta t=3$ months, we obtain $Q_{\text {anom }} \approx 40 \mathrm{~W} \mathrm{~m}^{-2}$. This is approximately onethird of the climatological-mean winter oceanic heat loss in the SAMW formation area of the southeast Pacific $\left(\sim 120 \mathrm{~W} \mathrm{~m}^{-2}\right)$ estimated by Grist and Josey (2003), and it is comparable to the interannual variability in the regional winter oceanic heat loss in the ERA-40 reanalysis for the period 1978-2002 (53-139 $\mathrm{W} \mathrm{m}^{-2}$, with a standard deviation of $20 \mathrm{~W} \mathrm{~m}^{-2}$; the NCEP-NCAR reanalysis displays similar variability). Thus, it is suggested that, in the southeast Pacific-Drake Passage region, the observed interannual variations in SAMW potential temperature may be plausibly and predominantly supported by changes in air-sea turbulent heat fluxes, although the Ekman heat flux contribution is likely nontrivial. 
a)

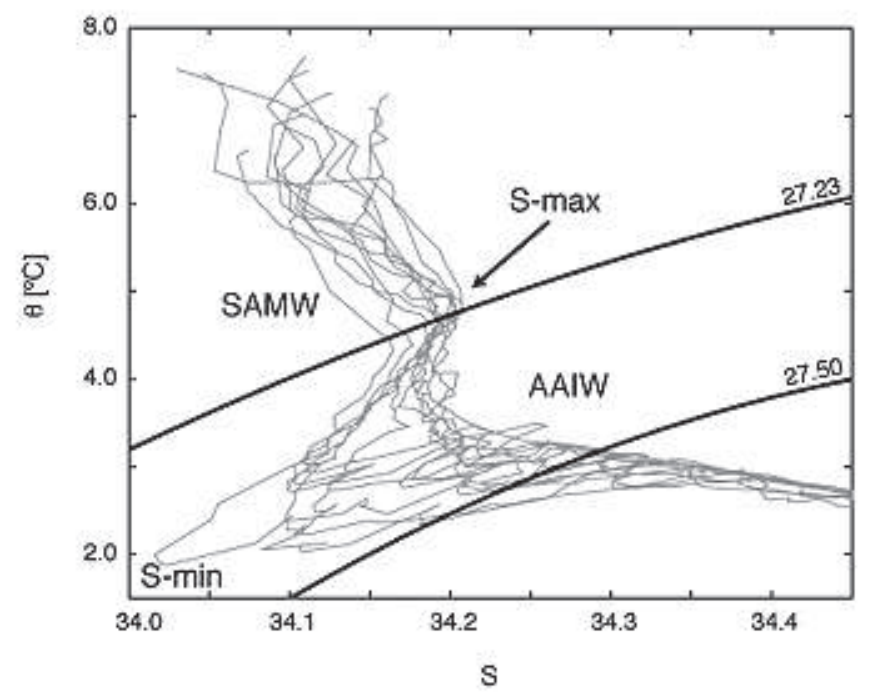

b)

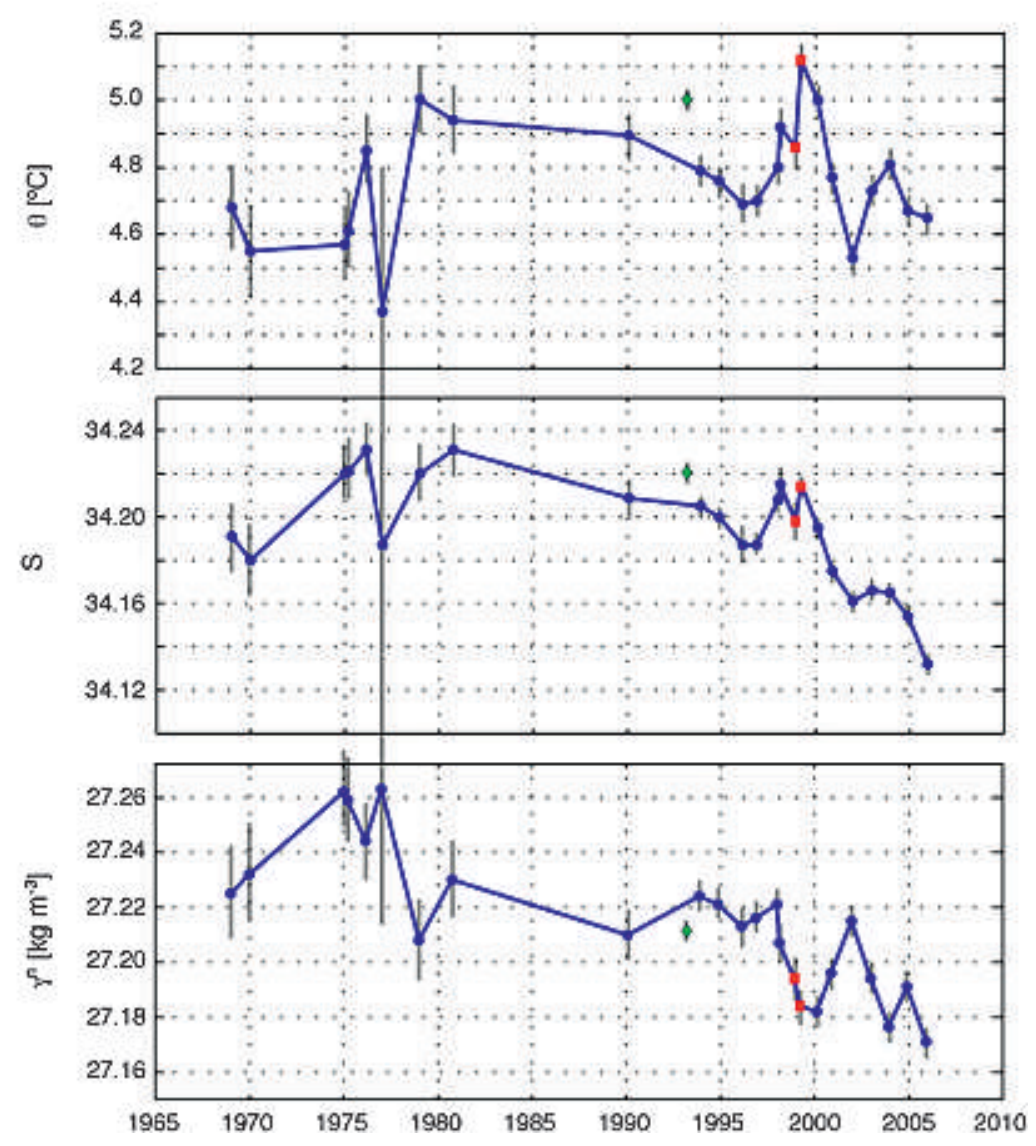

FIG. 6. (a) Illustrative $\theta-S$ relation (in gray) for the segment north of the PF in the 1997/98 WOCE SR1b section. The isopycnals separating SAMW, AAIW, and upper CDW are indicated by black lines and labeled. The $S$ maximum ( $S$-max) at the base of SAMW and the $S$ minimum $(S$-min) at the core of AAIW are marked. (b) Time series of $\theta, S$, and $\gamma^{n}$ on the $S$ maximum at the base of SAMW. The color and shape coding of symbols follows the convention set in Fig. 3; (b) is scaled such that $\theta$ and $S$ variations of the same graphical amplitude have equal impact on $\gamma^{n}$. 


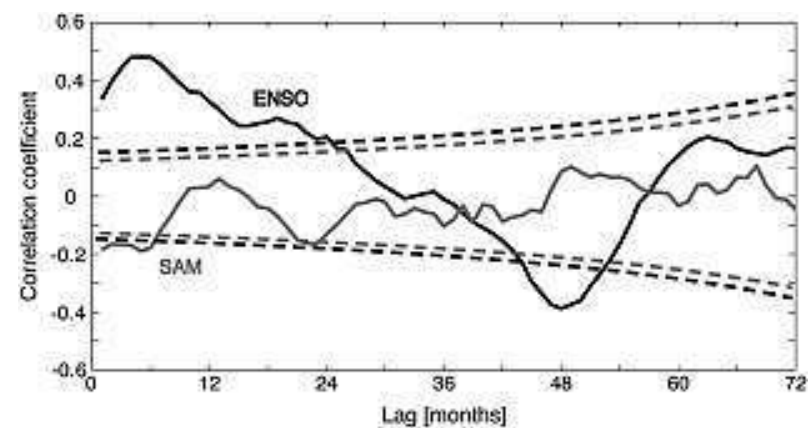

FIG. 7. Lagged cross correlations between a time series (19822006) of the monthly mean SST averaged over the SAMW formation region in the southeast Pacific-Drake Passage (defined by the $95 \%$ significance contour in Fig. 5) and monthly-mean indices of ENSO (solid black line) and the SAM (solid gray line). The $95 \%$ significance levels of the correlations are indicated by the dashed lines. Note the significant double-peak structure of each of the lagged correlations at lags of $2 \mathrm{yr}$ and shorter than $2 \mathrm{yr}$. The significant peak at longer lags most likely reflects the intrinsic periodicity in ENSO rather than a genuine physical link to southeast Pacific-Drake Passage SST.

This conclusion also applies to the measured year-toyear variations in SAMW salinity $\left(S_{\text {anom }}\right)$, which correspond to a winter-mean net precipitation anomaly $\left(F_{\text {anom }}\right)$ of $F_{\text {anom }}=h_{\mathrm{m}} S_{\text {anom }} S_{f}^{-1} \Delta t^{-1}$, where $S_{f}$ is the salinity after modification. Using $S_{\text {anom }} \approx 0.015$ and $S_{f} \approx$ 34.17 , we obtain $F_{\text {anom }} \approx 2 \times 10^{-8} \mathrm{~m} \mathrm{~s}^{-1} \approx 0.6 \mathrm{~m} \mathrm{yr}^{-1}$, which is broadly comparable to both the climatologicalmean winter net evaporation value of $\sim 2 \times 10^{-8} \mathrm{~m} \mathrm{~s}^{-1}$ estimated by Josey et al. (1998) and the interannual variability in the regional winter net evaporation in the ERA-40 reanalysis between 1978 and $2002\left(2.0 \times 10^{-8}\right.$ to $4.5 \times 10^{-8} \mathrm{~m} \mathrm{~s}^{-1}$ with a standard deviation of $0.7 \times$ $10^{-8} \mathrm{~m} \mathrm{~s}^{-1}$; the NCEP-NCAR reanalysis suggests somewhat weaker variability). Accounting for the same $S_{\text {anom }}$ with a change in the winter-mean Ekman freshwater transport across the southern edge of the SAMW formation region would require a questionably large zonal wind stress anomaly there. Following Rintoul and England (2002), this anomaly can be expressed as $\tau_{\text {anom }}^{x}=\rho_{0} f L_{y} h_{m} S_{\text {anom }}\left(S_{f}-S_{\mathrm{Ek}}\right)^{-1} \Delta t^{-1}$, where $f$ is the inertial frequency, $L_{y}$ is the meridional extent of the newly formed SAMW, and $S_{\mathrm{Ek}}$ is the salinity of the AASW flowing northward in the Ekman layer. Using $f \approx 1.2 \times 10^{-4} \mathrm{~s}^{-1}, L_{y} \approx 350 \mathrm{~km}$, and $S_{\mathrm{Ek}} \approx 34.0$, we obtain $\tau_{\text {anom }}^{x} \approx 0.2 \mathrm{~N} \mathrm{~m}^{-2}$, which is significantly larger than the climatological winter-mean zonal wind stress of $\sim 0.1 \mathrm{~N} \mathrm{~m}^{-2}$ estimated by Josey et al. (1998) and nearly an order of magnitude greater than the interannual variability in the regional winter-mean zonal wind stress in the ERA-40 reanalysis for the period of 1978-2002 $\left(0.07-0.26 \mathrm{~N} \mathrm{~m}^{-2}\right.$, with a standard deviation of 0.04 $\mathrm{N} \mathrm{m}^{-2}$ ). This result can be reconciled with Rintoul and
England's contrasting view on the dominance of the Ekman freshwater transport in shaping the interannual variability of SAMW salinity south of Australia by noting that the meridional upper-ocean salinity gradient in that region is much sharper than in the southeast Pacific-Drake Passage. Here, the density-compensating tendency of $\theta$ and $S$ variations seen in Fig. 6 does not necessarily imply a major Ekman contribution to the SAMW heat and freshwater budgets but may instead be a consequence of the dominance of ENSO in regulating winter mixed layer properties in the area.

Thus, El Niño (La Niña) events have been shown to be associated with positive (negative) anomalies in winter-mean evaporation in the region (Trenberth and Caron 2000; Curtis and Adler 2003) as well as positive (negative) anomalies in the air-sea turbulent heat flux (Verdy et al. 2006; Meredith et al. 2008). These associations can be characterized in terms of the influence exerted by the ENSO-related expansion and contraction of the west Pacific warm pool on the position of the South Pacific convergence zone (SPCZ), a band of lowlevel convergence, cloudiness, precipitation, and enhanced SST gradient extending southeastward from the warm pool region across the subtropical South Pacific (Folland et al. 2002). A northeastward (southwestward) migration of the SPCZ around its mean position has been shown to occur in response to El Niño (La Niña) events, perturbing the general atmospheric circulation of the midlatitude South Pacific (e.g., Turner 2004) and leading to a meridional displacement of large-scale SST and precipitation patterns.

The above characterization of the wind-driven Ekman flow as a secondary factor in forcing interannual changes in the SAMW of the southeast Pacific-Drake Passage has one notable omission. In 1998/99, unlike in the rest of our time series, two significant modes of SAMW were observed (Fig. 3). This can be seen in greater detail in Fig. 9, showing $\theta, S, p, \mathrm{O}_{2}$, and $\mathrm{Si}$ anomalies along a section occupied in the late summer of 1998/99 as a function of $\varphi$ and $\gamma^{n}$. The warmest, saltiest, and most $\mathrm{O}_{2}$ - and Si-depleted northern mode (found to the north of $\varphi \approx 0.8 \mathrm{~m}^{2} \mathrm{~s}^{-2}$ in Fig. 9 and shown by the red squares in Fig. 3) likely resulted from anomalously weak early winter convection in the southeast Pacific associated with the closing phase of the pronounced El Niño of 1997/98 (see Fig. 3, bottom). In contrast, the formation of the volumetrically dominant (colder and fresher) southern mode observed in 1998/99 (found to the south of $\varphi \approx 0.8 \mathrm{~m}^{2} \mathrm{~s}^{-2}$ in Fig. 9 and shown by the blue circles in Fig. 3) implicated an exceptionally strong northward Ekman injection of cool, fresh, high- $\mathrm{O}_{2}$, and high-Si AASW across the southern flank of the SAMW formation region in the southeast Pacific-Drake Passage. 

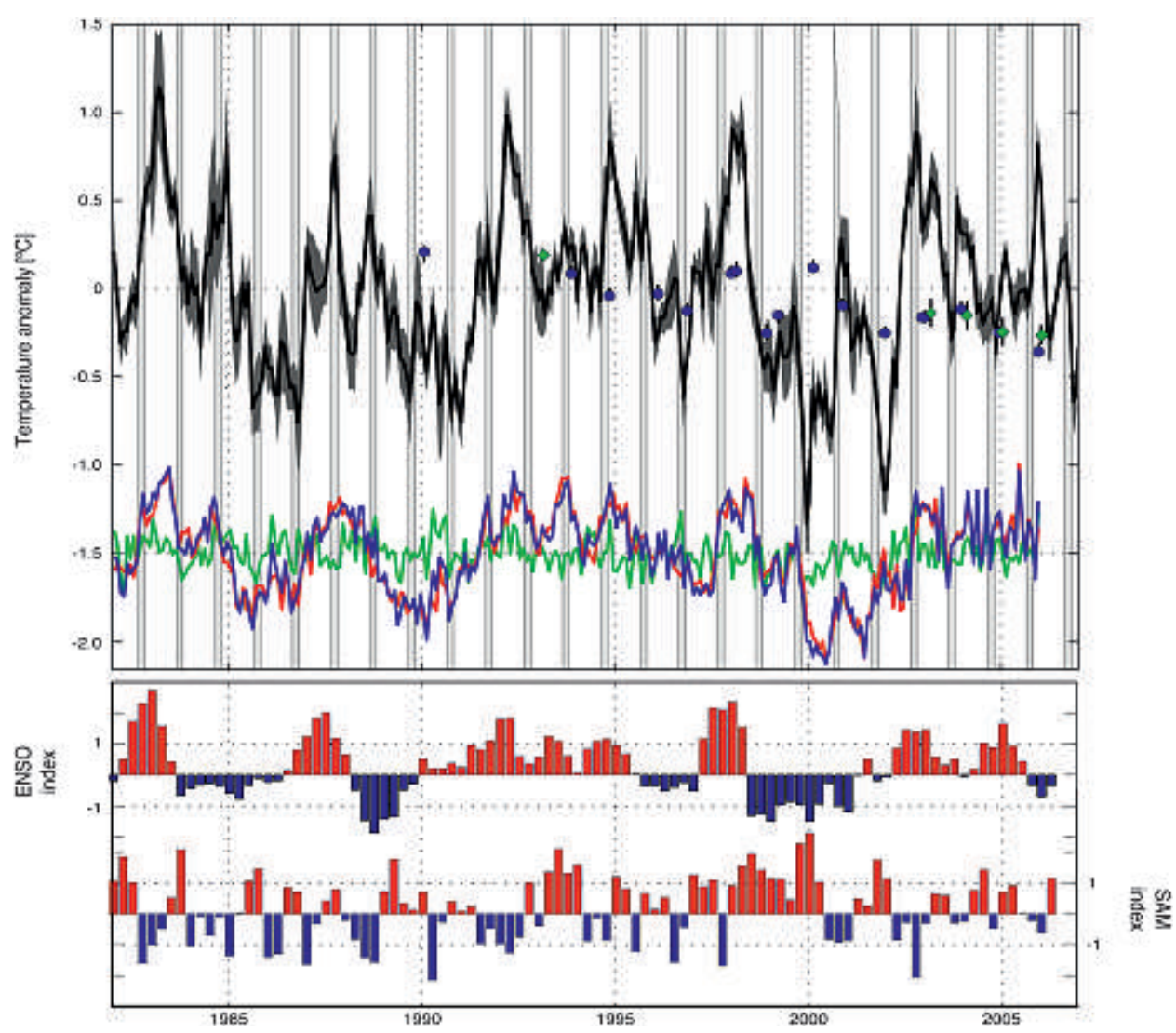

FIG. 8. (top) Time series of the monthly SST anomaly (black line) averaged over the SAMW formation region in the southeast Pacific-Drake Passage (defined by the $95 \%$ significance contour in Fig. 5) and the standard deviation of the spatial variability in monthly SST (dark gray shading). The red, green, and blue lines display linear regressions of the SST time series against the ENSO index, the SAM index, and both the ENSO and SAM indices, respectively, in which each index enters the regression with two lags [see section $4 \mathrm{a}(1)$ ]. Winter (July-September) periods are highlighted by vertical bands of light gray shading. SAMW potential temperature anomaly is shown by the blue circles and green diamonds, with the color and shape coding of symbols following the convention set down in Fig. 3. (bottom) Time series of the ENSO and SAM indices.

This Ekman injection is unique in our time series and was apparently forced by a very large eastward wind stress anomaly of $0.05-0.1 \mathrm{~N} \mathrm{~m}^{-2}$ that was centered to the north of the SAF in the southeast Pacific in the midand late winter of 1998 (Fig. 10). This outstanding anomaly was caused by the constructive interference of strongly positive SAM and negative ENSO forcings. As shown in the bottom of Fig. 3 and discussed by Visbeck (2009), the SAM attained one of its most extreme positive states in at least a century during 1998, at a time when the westerlies in the midlatitude southeast Pacific were being accelerated by a rapid transition from a strong El Niño to a marked La Niña state (see also Turner 2004). We suggest that the exceptional eastward wind stress anomaly that occurred in 1998 triggered a transitory shift in the SAMW formation regime of the southeast Pacific, away from the usual convection- driven mode of ventilation. During that winter, intense destruction of PV north of the SAF may have been forced by strong alongfront winds (Thomas 2005), which at the time exceeded $0.1 \mathrm{~N} \mathrm{~m}^{-2}$ in the region. A dominance of this mechanism would not only be coherent with the generation of an AASW-influenced southern mode of SAMW in 1998 but may also underlie the occurrence of record-maximum pressures and Si concentrations and record-minimum $\mathrm{PV}$ and $\mathrm{O}_{2}$ values in both of the SAMW modes produced that year (Figs. 3, 9). This point is most clearly illustrated by the relationship between the thermohaline anomalies and the pressure (or PV) anomaly of the northern mode of SAMW in 1998, which is opposite to that in the rest of our time series (section 3).

Because the production of Ekman-influenced southern modes of SAMW apparently depends on the interference 


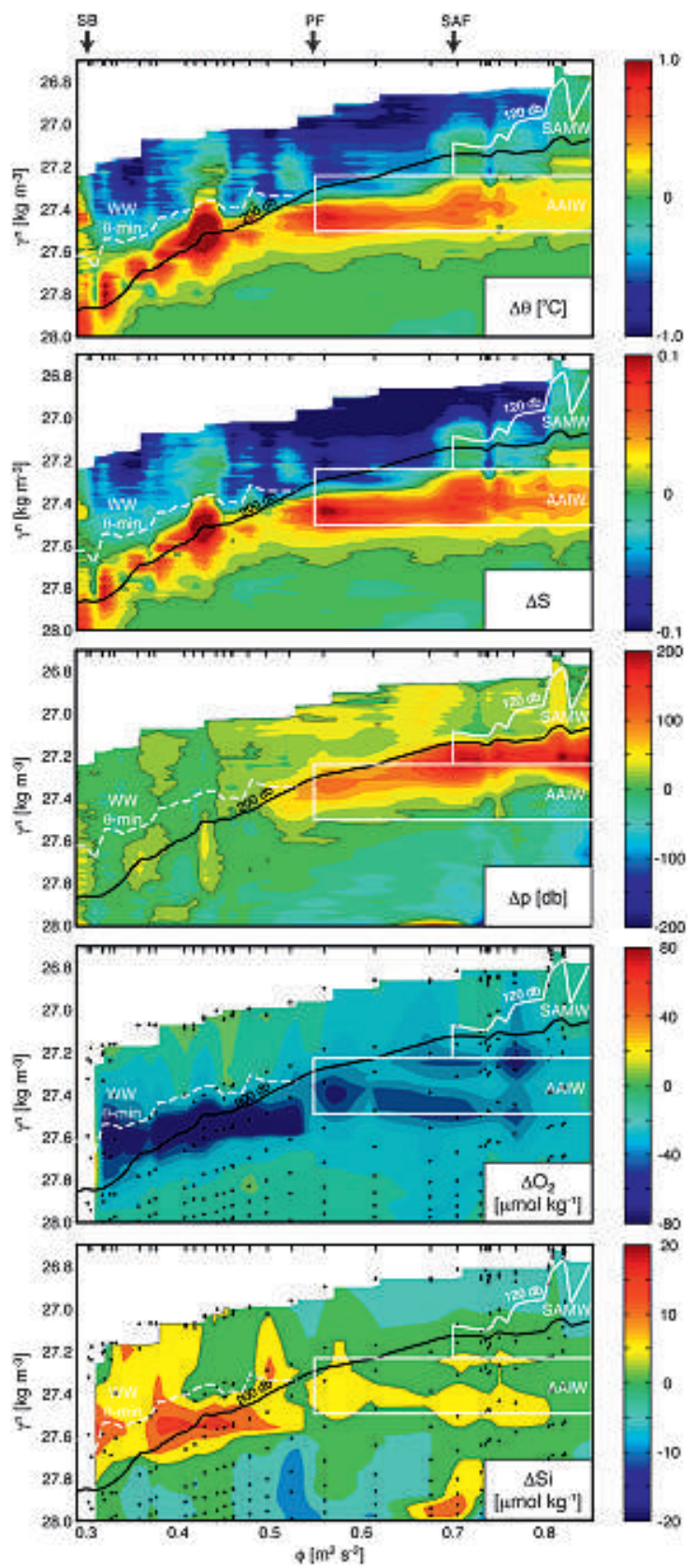

FIG. 9. Distributions of the $\theta, S, p, \mathrm{O}_{2}$, and $\mathrm{Si}$ anomalies (in color) across the Drake Passage during the WOCE SR1W transect in March 1999 (Table 1). Anomalies are calculated by subtracting the mean $\theta, S$, and $p\left(\mathrm{O}_{2}\right.$ and $\left.\mathrm{Si}\right)$ distributions averaged over the 24 (11) sections in which those variables were measured from the March 1999 fields. The $p=200$-dbar contour (which typically lies at the base of the winter mixed layer south of the PF) in 1999 is shown in black. The regions of $\varphi-\gamma^{n}$ space used in our analysis of SAMW and AAIW (see section 3 ) are delimited by the closed white lines. The $\theta$ minimum of Winter Water is marked by the dashed white lines and labeled. Station positions are denoted by tick marks on the upper axis. (top) The SAF, PF, and SB are marked by arrows. between a strongly negative ENSO state and a markedly positive SAM state, we contend that the SAMW formation regime of the southeast Pacific may be sensitive to decadal variations in the relative phasing of ENSO and the SAM. In the late 1970s and 1980s, no appreciable wintertime phase locking occurred between the two modes (Fogt and Bromwich 2006). In contrast, ENSO and the SAM were significantly in antiphase during the winter periods of 1990-2001. This scenario is favorable to the formation of southern modes of SAMW and provides a plausible explanation for the absence of southern mode-production events prior to the 1990s.

\section{2) Antarctic Intermediate Water}

The AAIW flowing through the Drake Passage is characterized by an $S$ minimum centered within the $27.23<\gamma^{n}<27.40 \mathrm{~kg} \mathrm{~m}^{-3}$ neutral density range. As widely noted before (e.g., Piola and Gordon 1989; Meredith et al. 1999), this feature likely reflects the northward intrusion of relatively cold and fresh AASW along isopycnals. Our observations of the evolving characteristics of AAIW in the Drake Passage during the last four decades are consistent with this notion, because they demonstrate that the interannual variability of the regional AAIW properties is primarily driven by changes in the characteristics of AASW. This appears at odds with the proposition that SAMW in the southeast Pacific may play a leading role in AAIW formation (McCartney 1977; see also Talley 1996).

Evidence in support of this assertion is provided by Fig. 11a, which shows the correlation between the $\theta$ of the AAIW measured in the Drake Passage during the summers of 1989/90-2005/06 (Fig. 4) and SST in each of the previous winters. A region of significant positive correlation extends zonally between the western edge of the Antarctic Peninsula and $105^{\circ} \mathrm{W}$ and meridionally between $70^{\circ} \mathrm{S}$ and the $\mathrm{PF}$ near $62^{\circ} \mathrm{S}$, suggesting that temperature anomalies in the winter variety of AASW in this area of the southeast Pacific lead anomalies of the same sign in the AAIW of the Drake Passage by several months. The specific association between AAIW properties and the characteristics of AASW in winter (and not in other seasons) comes about because it is only in wintertime that the density range of the AAIW salinity minimum outcrops at the surface and is ventilated within the ACC. The properties of this so-called Winter Water persist until the following winter in a subsurface remnant mixed layer that subducts at the PF throughout the year, driven by a combination of direct wind forcing and baroclinic instability of the frontal jet (Naveira Garabato et al. 2001). This conceptual model of AAIW ventilation upstream of the Drake Passage is consistent 
a) $s$

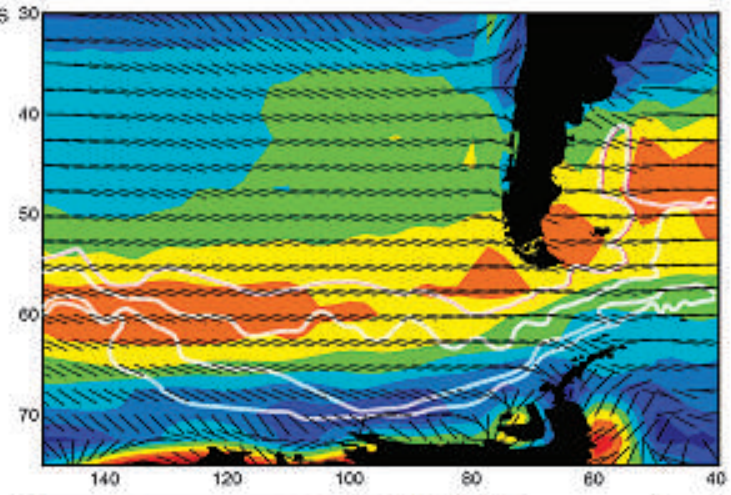

b)

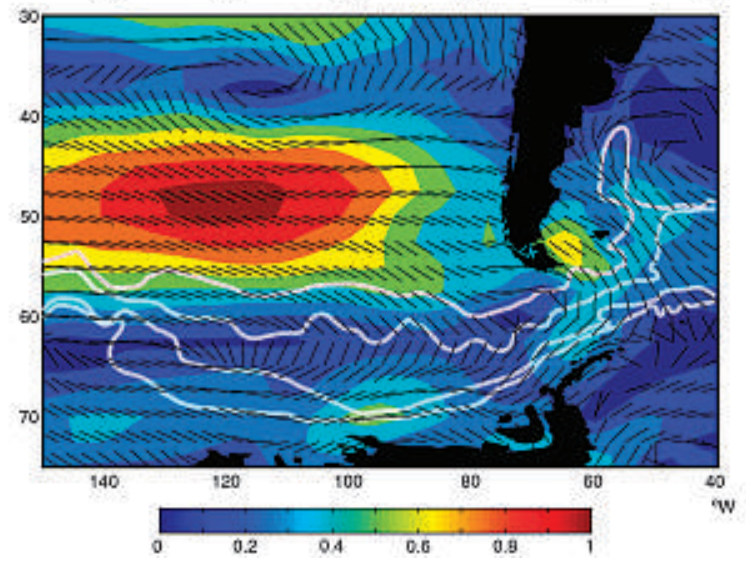

c)

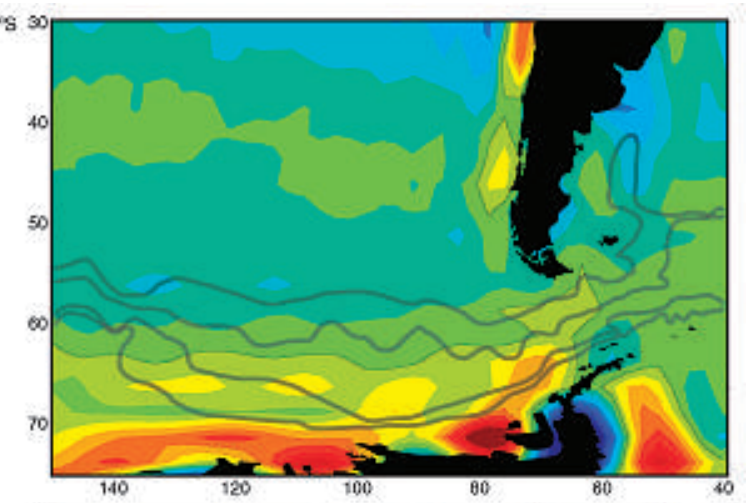

d)

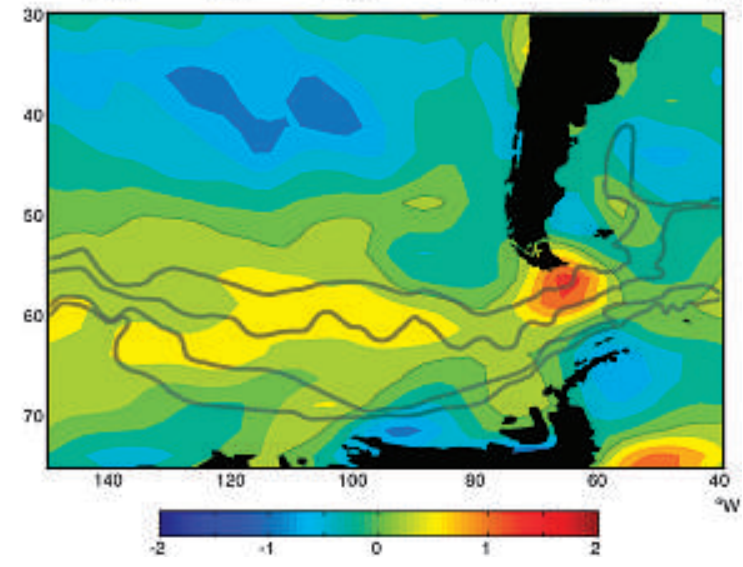

FIG. 10. Maps of NCEP-NCAR (a) winter- (July-September) mean wind stress magnitude (colors) and direction (vectors) for 19782006; (b) winter wind stress anomaly in 1998; (c) winter-mean Ekman vertical velocity for 1978-2006, corresponding to the wind field in (a); and (d) winter Ekman vertical velocity anomaly in 1998, corresponding to the wind field in (b). Climatological frontal positions are shown by thick (a),(b) white or (c),(d) gray lines.

with the evolution of Winter Water thermohaline characteristics in the sections analyzed here (Fig. 12). Interannual changes in the $\theta$ and $S$ of the AAIW found to the north of the PF in the Drake Passage mimic more ample fluctuations in the properties of the Winter Water $\theta$ minimum to the south of the $\mathrm{PF}$, pointing to a connection between the two water masses on subannual time scales.

A relationship analogous to that shown in Fig. 11a is found between the $\theta$ (and $S$ ) of AAIW and the preceding winter sea ice concentration in the region, as evidenced by the area of significant negative correlation stretching across the Bellingshausen Sea (Fig. 11b). This correspondence stems from the strong thermodynamic coupling that SST and sea ice concentration anomalies exhibit across the Southern Ocean on interannual time scales (e.g., Gloersen and White 2001). It implies that winters with anomalously warm (cold) Winter Water west of the Antarctic Peninsula are associated with anomalously low (high) sea ice concentration in the region, hence leading, upon northward subduction, to anomalously warm and saline (cold and fresh) AAIW in the Drake Passage the following summer. Previous studies (Harangozo 2006; Meredith et al. 2008) have established that the interannual variability in the SST and sea ice extent of the Bellingshausen Sea is strongly forced by meridional winds west of the Antarctic Peninsula. There, the meridional alignment of the continent prevents eastward ice drift in response to the prevailing westerlies and causes meridional winds to be particularly effective in controlling sea ice extent, with ice formation and melting in the marginal ice zone and surface ocean circulation having a lesser influence.

The regulatory role exerted by meridional winds on SST and sea ice extent in the Bellingshausen Sea carries over to our discussion of the interannual variability of AAIW in the Drake Passage. As illustrated by Fig. 11c, there is a significant negative correlation between the meridional wind stress off the western Antarctic Peninsula in winter and the $\theta$ (and $S$ ) of AAIW in the Drake Passage the subsequent summer, such that enhanced wind-induced northward sea ice export is conducive to anomalously cold and fresh AAIW in the Drake Passage and vice versa. There is no significant correlation (at any lag) between the measured changes in AAIW 
a)

b)

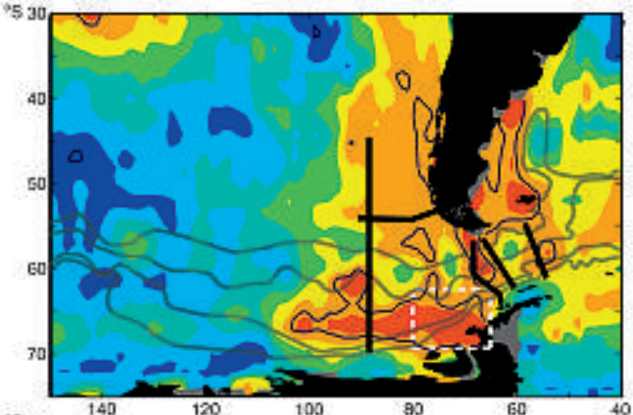

c)
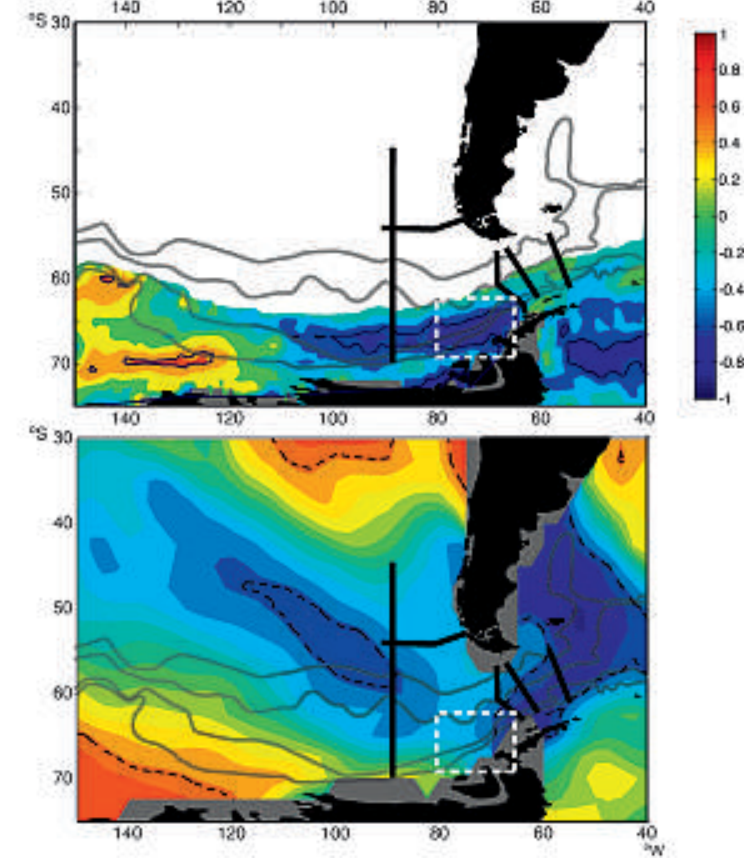

FIG. 11. Maps of the correlation between year-to-year changes in the spring-summer $\theta$ of AAIW in the Drake Passage and interannual variations in (a) the preceding winter-mean SST (with winter defined as July-September), (b) the preceding winter-mean sea ice concentration, and (c) the NCEP-NCAR preceding wintermean meridional wind stress. Correlation is given in color. Significance at the $95 \%$ level is denoted by the solid black contours. Significance at the $90 \%$ level is indicated by the dashed black contours in (c). Climatological frontal positions and section locations (Fig. 1) are shown by thick gray and black lines, respectively. The Bellingshausen Sea control area, in which we judge that the Winter Water ventilating the AAIW layer upstream of the Drake Passage originates, is delimited by the dashed white line.

properties and zonal wind stress anomalies in the southeast Pacific-Drake Passage region, suggesting that windinduced variability of the rate of subduction of Winter Water is not a major driver of interannual variations in AAIW characteristics. It thus appears that the shoaling and thickening (deepening and thinning) of the AAIW layer that characterizes the production of cold and fresh (warm and saline) varieties of the water mass are, for the most part, passive responses to the concurrent deepening (shoaling) experienced by SAMW [section 4a(1)].
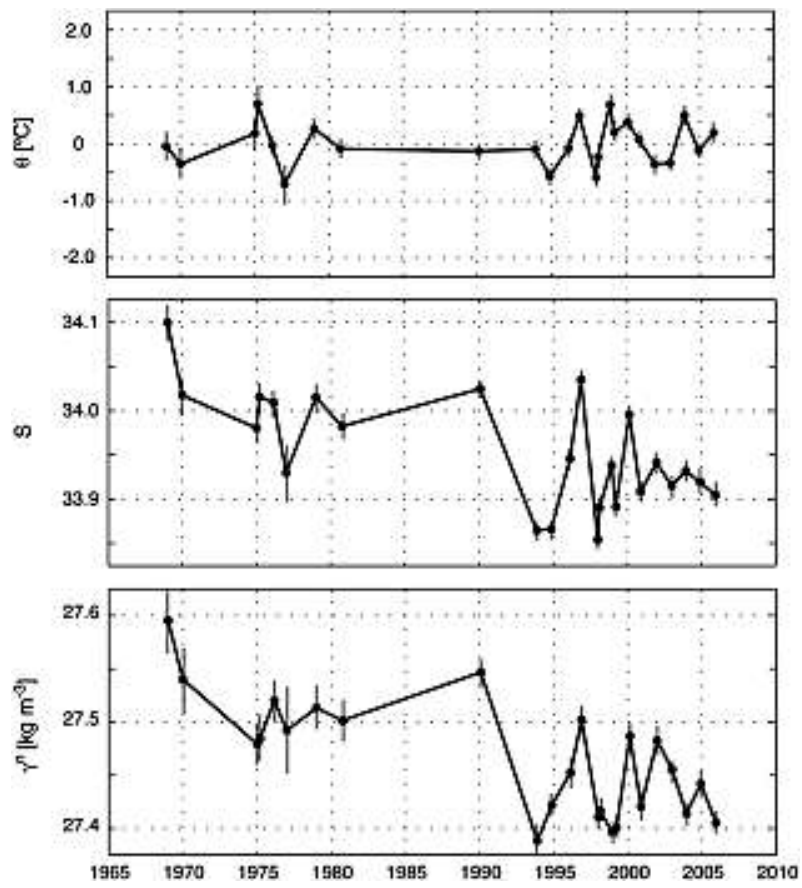

FIG. 12. Time series of $\theta, S$, and $\gamma^{n}$ on the $\theta$ minimum at the core of the Winter Water south of the PF (see, e.g., Fig. 2). The displayed values are averages over the sector with $0.3<\varphi<0.5 \mathrm{~m}^{2} \mathrm{~s}^{-2}$. The scale is such that $\theta$ and $S$ variations of the same graphical amplitude have equal impact on $\gamma^{n}$.

This inference is consistent with our observation (not shown) of minimal variability in the pressure of the lower boundary of AAIW in the Drake Passage over the entire record.

The interannual variability in AAIW salinity seen in Fig. 4 does not result exclusively from examining property changes on isopycnals in the presence of variations in $\theta$ but genuinely reflects changes in the $S$ of the AASW found to the west of the Antarctic Peninsula in winter. This is demonstrated in Fig. 13, which shows the potential temperature, salinity, and neutral density of the $S$ minimum marking the core of AAIW (Fig. 6). Although $\theta$ (and $\gamma^{n}$ ) is somewhat noisy because of its sensitivity to mesoscale interleaving, the record in Fig. 13 shows qualitatively similar thermohaline variability on interannual time scales to that seen in AAIW on isopycnal surfaces (Fig. 4) and, by extension, in the $\theta$ minimum of the Winter Water to the south of the PF (Fig. 12). The $\theta$ and $S$ of the AAIW salinity minimum vary in a partially density-compensating manner, with $\theta$ fluctuations being dominant in determining year-to-year changes in density. This is consistent with the proposed prevalence of northward subduction of Winter Water in the ventilation of the AAIW flowing through the Drake Passage, because the occurrence of density-compensated thermohaline variability is a well-understood characteristic 

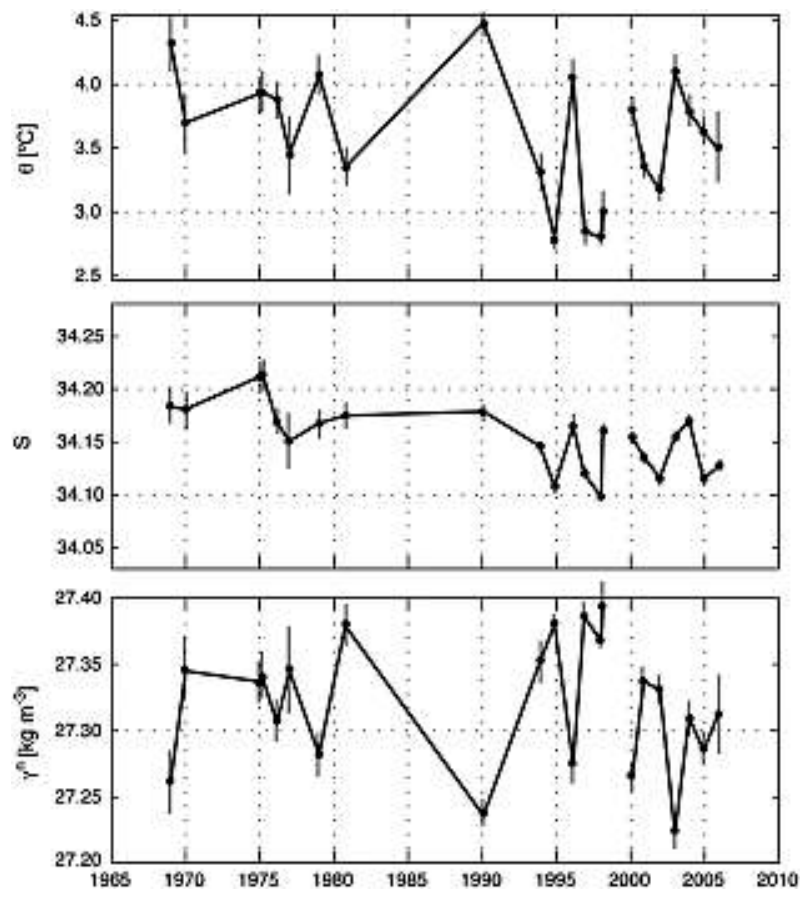

FIG. 13. Time series of $\theta, S$, and $\gamma^{n}$ on the $S$ minimum at the core of AAIW (see Fig. 6a). The scale is such that $\theta$ and $S$ variations of the same graphical amplitude have equal impact on $\gamma^{n}$.

of mixed layer water masses (e.g., Ferrari and Paparella 2003 ) that is reflected in the evolution of Winter Water properties (although note that, unlike for AAIW and because of the nonlinear nature of the equation of state for seawater, $S$ fluctuations are primarily responsible for interannual changes in Winter Water density; see Fig. 12). The absence of an $S$ minimum in the AAIW of $1998 / 99$ is remarkable and suggests that subduction of Winter Water was temporarily arrested during that period. The dynamics of this extraordinary event are discussed in the next subsection.

To understand how the observed interannual variability of AAIW is forced by fluctuations in the Southern Ocean climate system, we examine the relationships of Winter Water temperature, sea ice extent, and meridional winds off the western Antarctic Peninsula to the states of ENSO and the SAM. As described in detail by Meredith et al. (2008), both of these modes of variability exert a notable influence on the meridional wind stress in the Bellingshausen Sea. El Niño (La Niña) states of ENSO in the tropical Pacific Ocean induce, via the Pacific-South American pattern, a short-lag positive (negative) surface atmospheric pressure anomaly in the southeast Pacific that is associated with unusually strong (weak) southerly winds off the western Antarctic Peninsula (Turner 2004; see also Meredith et al. 2008, their Fig. 13). The SAM, in turn, exhibits its most prominent departure from zonal symmetry in the Bellingshausen Sea region, where topographic barriers project SAMrelated wind fluctuations onto a cyclonic pattern (e.g., Lefebvre et al. 2004). As a consequence, positive (negative) SAM states are linked with anomalously weak (strong) southerly winds west of the peninsula on a range of time scales (see Meredith et al. 2008, their Fig. 12). Figure 14 shows that, in wintertime and to a lesser extent throughout the rest of the year, these relationships translate into an occurrence of positive (negative) anomalies in sea ice extent and negative (positive) anomalies in AASW temperature during El Niño and negative SAM states (La Niña and positive SAM states). These changes in Winter Water properties are then imprinted on the AAIW observed the following spring and summer.

The relative significance of ENSO and the SAM in forcing interannual changes in AAIW characteristics can be assessed by gauging the extent to which each of them drives observed variations in SST and sea ice cover in the Bellingshausen Sea. To do this, we define a control area bounded by $63^{\circ}-69^{\circ} \mathrm{S}, 65^{\circ}-80^{\circ} \mathrm{W}$ in which we judge that the Winter Water ventilating the AAIW layer upstream of the Drake Passage must originate if it is to subduct at the PF within a few months after winter, given representative along- and across-ACC surface velocities of $O\left(0.05 \mathrm{~m} \mathrm{~s}^{-1}\right)$ and $O\left(0.01 \mathrm{~m} \mathrm{~s}^{-1}\right)$. This control area is embedded in the region of significant correlation between AAIW potential temperature and previous-winter SST and sea ice extent found to the west of the Antarctic Peninsula (Fig. 11). Our results are insensitive to the detailed choice of control area bounds. A lagged cross-correlation analysis between the time series (1982-2006) of monthly-mean SST averaged over the control area and monthly-mean indices of ENSO and the SAM (Fig. 15) reveals that SST responds to both modes with a short lag of 0-3 months. ENSO is the dominant driver of month-to-month SST variability and displays a peak significant anticorrelation of 0.45 , whereas the SAM exerts a weaker but significant influence that manifests itself in a maximum correlation in excess of 0.15. Quantitatively similar relationships with ENSO and the SAM are diagnosed for sea ice extent (Fig. 15) and meridional wind stress (not shown) in the region. The same pattern of ENSO dominance is inferred with a cross-correlation analysis of winter-mean variables (not shown). A linear regression of the SST (sea ice extent) time series against the ENSO and SAM indices, each with zero lag, reveals that the reconstructed SST (sea ice extent) can explain 23\% (22\%) of the variance in the original time series (Fig. 14). All in all, we conclude that ENSO is a major driver of interannual thermohaline variability in the region west of the 
a)

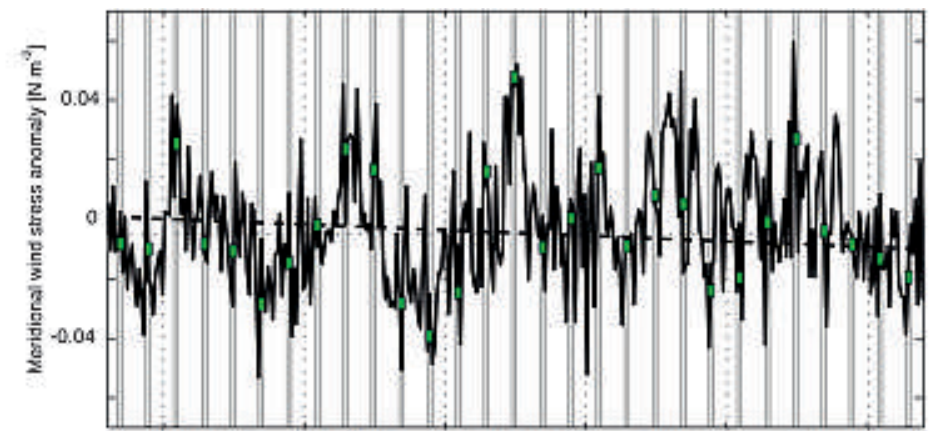

b)

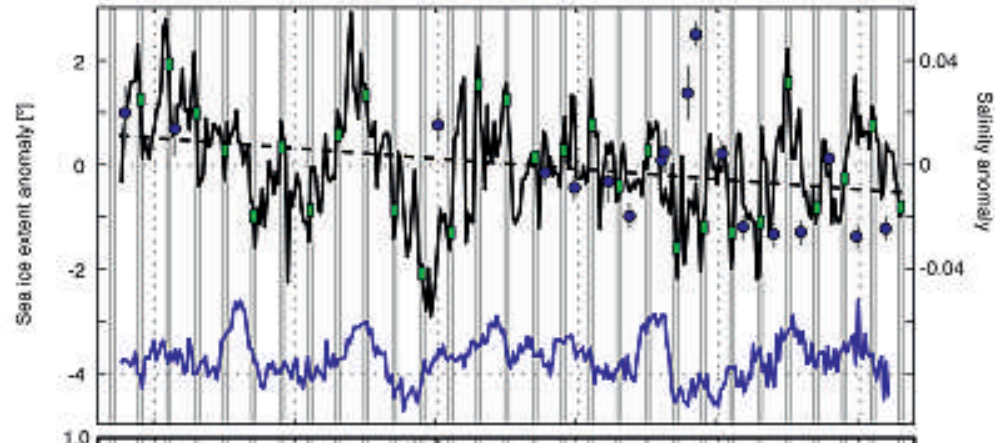

c)

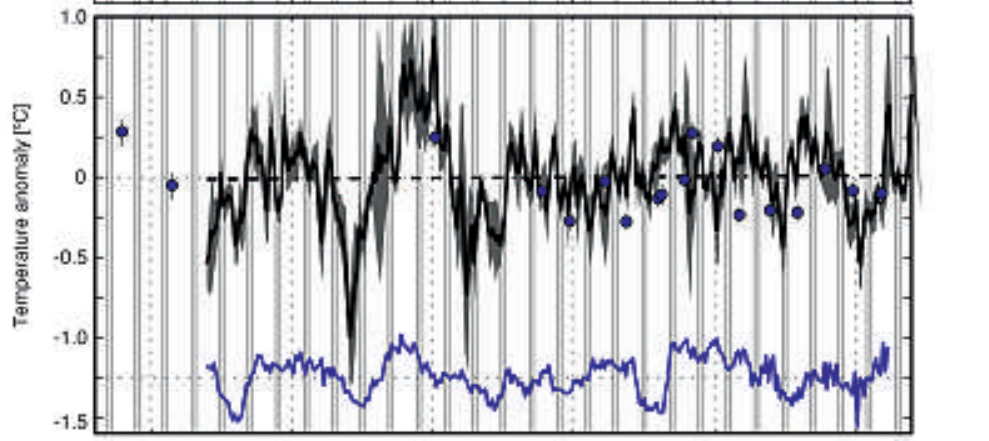

d)

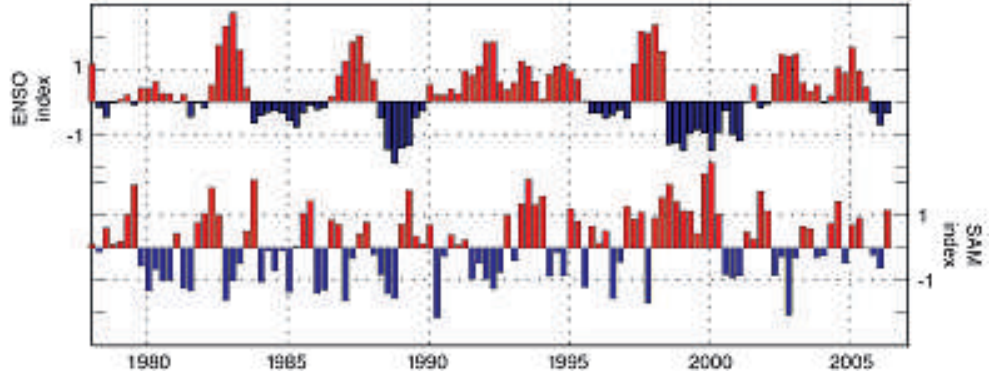

FIG. 14. Time series of NCEP-NCAR (a) meridional wind stress anomaly, (b) sea ice extent anomaly, and (c) SST anomaly (black lines) averaged over the Bellingshausen Sea control area defined in Fig. 11. Early winter (June-August) periods are highlighted by vertical bands of light gray shading in (a), and late winter (July-September) periods are similarly marked in (b) and (c). Early-winter-mean meridional wind stress anomalies and late-winter-mean sea ice extent anomalies are shown by the green rectangles in (a) and (b), and the standard deviation of the spatial variability in monthly SST is given by the dark gray shading in (c). Linear trend fits to the time series of early-winter-mean meridional wind stress anomalies and late-winter-mean sea ice extent and SST anomalies are shown by the dashed lines. Drake Passage AAIW $S$ and $\theta$ anomalies are indicated by the blue circles in (b) and (c), respectively. The blue lines in (b) and (c) display linear regressions of the sea ice extent anomaly and SST anomaly time series against the ENSO and SAM indices, where both indices enter the regression with zero lag [see section $4 \mathrm{~b}(1)$ ]. Time series of the ENSO and SAM indices are shown in (d). 


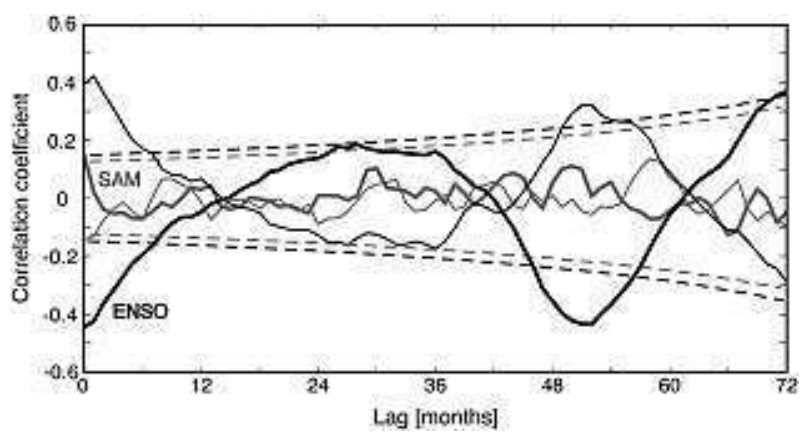

FIG. 15. Lagged cross correlations between a time series (19822006) of the monthly-mean SST (thick solid lines) averaged over the Bellingshausen Sea control area defined in Fig. 11 and monthly-mean indices of ENSO (black) and the SAM (gray). The equivalent cross correlations between a time series of sea ice extent in the area and the ENSO and SAM indices are shown by the black and gray thin solid lines, respectively. The $95 \%$ significance level of the correlations is indicated by the dotted black lines. Note the significant peaks in all of the lagged correlations at lags of 0-3 months. Significant peaks at longer lags most likely reflect intrinsic periodicities in ENSO rather than a genuine physical link to surface water and sea ice properties in the Bellingshausen Sea.

Antarctic Peninsula where the properties of the Winter Water ventilating the AAIW layer in the Drake Passage are set, with the SAM exerting a secondary impact.

The heat and freshwater budgets of this Winter Water are complex. The presence of sea ice and the distinct air-sea-ice interaction regimes that likely prevail in the coastal and open-ocean sectors of the Bellingshausen Sea make it difficult to constrain the budgets quantitatively with the available information. The close correspondence that is observed between interannual changes in winter-mean meridional wind stress, sea ice extent, and SST (Fig. 14) points to a key role of winds in forcing variations in regional Winter Water properties. Given that the contribution of wind-driven Ekman advection of near-freezing surface waters from the south into the control area is an order of magnitude too small to explain interannual variations in winter-mean SST, ${ }^{2}$ we contend that the correspondence between wintertime meridional wind stress and SST is indicative of a dominance of air-sea turbulent heat fluxes in the heat budget of the Winter Water. Thus, when winter-mean

\footnotetext{
${ }^{2}$ The contribution of the wind-driven Ekman flow to forcing interannual anomalies in the potential temperature of Winter Water in the control area may be estimated as $\theta_{\text {anom }}=\tau_{\text {anom }}^{x}\left(\theta_{\mathrm{f}}-\right.$ $\left.\theta_{\text {Ek }}\right)\left(\rho_{0} f L_{y} h_{m}\right)^{-1} \Delta t$. Using $\tau_{\text {anom }}^{x} \approx 0.04 \mathrm{~N} \mathrm{~m}^{-2}$ (estimated from the ERA-40 reanalysis), $\theta_{\mathrm{f}} \approx-0.5^{\circ} \mathrm{C}$ and $\theta_{\mathrm{Ek}} \approx-1.7^{\circ} \mathrm{C}$ (estimated from the wintertime SST distribution), $\rho_{0}=1027 \mathrm{~kg} \mathrm{~m}^{-3}, f=1.3 \times$ $10^{-4} \mathrm{~s}^{-1}, L_{y} \approx 550 \mathrm{~km}, h_{m} \approx 150 \mathrm{~m}$, and $\Delta t=3$ months, we obtain $\theta_{\text {anom }} \approx 0.03^{\circ} \mathrm{C}$, which is an order of magnitude less than observed interannual changes in winter-mean SST (Fig. 14).
}

meridional wind stress exhibits a positive (negative) anomaly, relatively cold Antarctic (warm oceanic) air masses will be displaced northward (southward) across the Bellingshausen Sea and induce an anomalous turbulent heat flux out of (into) the ocean. If air-sea turbulent heat fluxes were to fully account for the observed year-to-year $\theta$ variations in the Winter Water (typically $\theta_{\text {anom }} \approx 0.5^{\circ} \mathrm{C}$; Figs. 12,14 ), their winter-mean anomalous value would have to be on the order of $Q_{\text {anom }} \approx 50$ $\mathrm{W} \mathrm{m}^{-2}$. This possibility is admitted by the ERA-40 reanalysis for the 1978-2002 period, which displays comparable interannual variability in the winter-mean airsea turbulent heat flux in the control area (43-91 $\mathrm{W} \mathrm{m}^{-2}$, with a standard deviation of $22 \mathrm{~W} \mathrm{~m}^{-2}$ ). Because the wintertime expansion of sea ice in the area is primarily driven by wind-induced ice drift from the south (Harangozo 2006) with local freezing playing a lesser role, little of the heat transferred across the air-sea interface through turbulent exchanges will be expended in sea ice formation.

Regarding the freshwater budget of the Winter Water, we infer that the wind-driven Ekman transport of freshwater from the south exerts a negligible influence in the interannual variability in $S$. In contrast, net evaporation may provide a nontrivial contribution to the budget. The winter-mean net precipitation anomaly required to account for the observed year-to-year $S$ changes in Winter Water $\left(S_{\text {anom }} \approx 0.05\right.$; Fig. 12$)$ is $F_{\text {anom }}$ $\approx 2.8 \times 10^{-8} \mathrm{~m} \mathrm{~s}^{-1}$, which is larger than but somewhat comparable to the interannual variability in the regional winter net evaporation in the ERA-40 reanalysis $(0.6 \times$ $10^{-8}$ to $2.1 \times 10^{-8} \mathrm{~m} \mathrm{~s}^{-1}$, with a standard deviation of $0.6 \times 10^{-8} \mathrm{~m} \mathrm{~s}^{-1}$ ). It seems unlikely, however, that this is the main process underlying interannual variations in the freshwater content of Winter Water and AAIW, particularly in view of the fact that, in the months following their formation, Winter Water anomalies are attenuated by mixing with surrounding water masses.

At the end of winter, the sea ice transported into the control area by the meridional winds begins to melt and provides a sink of heat and a source of freshwater to the Winter Water beneath. During its northward journey of several months toward the PF, where it subducts and ventilates the AAIW, the Winter Water will be modified by the admixture of the cold, fresh products of sea ice melt. The order of magnitude of this contribution to the heat and freshwater budgets of the Winter Water may be estimated by considering the interannual variations in winter sea ice extent $\left(d_{\text {anom }}\right)$, which exhibit typical magnitudes of $1^{\circ}-2^{\circ}$ latitude (Fig. 14). From these, the change in Winter Water temperature resulting from the melting of sea ice in spring may be estimated as $\theta_{\text {anom }} \approx\left(\theta_{c}-\theta_{i}-L_{c} c_{p}^{-1}\right) \rho_{c} \rho_{0}^{-1} h_{c a} h_{m}^{-1}$ 
[see, e.g., Watanabe et al. 2004, their Eq. (A8)], where $\theta_{c} \approx$ $-1.8^{\circ} \mathrm{C}$ is the temperature at the freezing point of seawater, $\theta_{i}$ is the potential temperature of the Winter Water before the melting event, $L_{c} \approx 2.93 \times 10^{5} \mathrm{~J} \mathrm{~kg}^{-1}$ is the latent heat of freezing, $\rho_{c} \approx 930 \mathrm{~kg} \mathrm{~m}^{-3}$ is the density of sea ice, and $h_{c a}$ is the sea ice thickness anomaly averaged over the area of Winter Water under consideration. Although the definition of this area is somewhat ambiguous, an order-of-magnitude estimate of $h_{c a}$ may be obtained by assuming that the bulk of the Winter Water ventilating the AAIW layer immediately upstream of the Drake Passage originates in the control area defined in Fig. 11, as argued above. In that case, $h_{c}$ may be approximated as $h_{c a} \sim h_{c} d_{\text {anom }} C L_{y}^{-1}$, where $h_{c} \sim 0.5-1 \mathrm{~m}$ is the typical sea ice thickness in the Bellingshausen Sea (Timmerman et al. 2004), $C \sim 0.6$ defines a characteristic late-winter sea ice concentration of the ice-covered sector of the control area, and $L_{y} \sim 550 \mathrm{~km}$ is the meridional extent of the area. Taking $\theta_{i} \sim-0.5^{\circ} \mathrm{C}$ (the SST observed in late winter near the northern edge of the control area) and $d_{\text {anom }} \sim 110-220 \mathrm{~km}$ (i.e., $1^{\circ}-2^{\circ}$ latitude), we obtain $\theta_{\text {anom }} \sim 0.03-0.11^{\circ} \mathrm{C}$. This suggests that sea ice melting in spring contributes nontrivially to driving interannual variability in Winter Water temperature, although it is seemingly less important than air-sea turbulent heat fluxes in winter. Regardless, both contributions are phase-locked to interannual variations in meridional wind stress west of the Antarctic Peninsula and must, as a result, reinforce each other's effects.

Similarly, the change in Winter Water salinity associated with the melting of sea ice can be estimated as $S_{\text {anom }} \approx$ $\left(\rho_{c} S_{c}-\rho_{0} S_{i}\right) \rho_{0}^{-1} h_{c a} h_{m}^{-1}$ [see, e.g., Watanabe et al. (2004), their Eq. (A4)], where $S_{c} \approx 5$ is the salinity of the sea ice and $S_{i} \sim 34.0$ is the salinity of the Winter Water before the melting event. We obtain $S_{\text {anom }} \sim 0.01-0.05$, a range of values that appear to be large enough to account for the observed interannual variability in Winter Water salinity. Thus, we deduce that sea ice melt is the most likely leading driver of year-to-year changes in the freshwater content of AAIW and that its phase-locking to meridional wind stress - and, therefore, air-sea turbulent heat fluxes-over the Bellingshausen Sea must play a part in the observed partially density-compensated character of AAIW thermohaline variability in Drake Passage. Our inference that wind-driven sea ice motion plays a central role in forcing variations in AAIW salinity is coherent with the findings of coupled climate model studies (Saenko and Weaver 2001; Santoso and England 2004).

\section{3) ARrest of ANTARCTIC INTERMEDiATE WATER FORMATION IN 1998/99}

Among all the interannual variations of AAIW properties in our time series, the temporary arrest of Winter
Water subduction in 1998/99 is outstanding and warrants special attention. We return to Fig. 9, which shows a section of the $\theta, S, p, \mathrm{O}_{2}$, and $\mathrm{Si}$ anomalies in the summer of 1998/99 relative to the mean distributions of those variables in all other sections as a function of $\varphi$ and $\gamma^{n}$. The anomalous AAIW layer-mean properties seen in Fig. 4 are evident in this section, which reveals that the bulk of AAIW was exceptionally warm, saline, deep, $\mathrm{O}_{2}$ poor, and $\mathrm{Si}$ rich in comparison to average conditions. The AAIW layer equatorward of the PF experienced a prominent thinning (i.e., an increase in PV) by $\sim 200 \mathrm{~m}$ that arguably occurred in response to the thickening of SAMW driven by intense down-SAF winds during the winter of 1998 (Fig. 10). Further, we note from Fig. 12 that the Winter Water was anomalously warm (by $\sim 0.5^{\circ} \mathrm{C}$ ) and light (by $\sim 0.1 \mathrm{~kg} \mathrm{~m}^{-3}$ ), as well as slightly fresh, in the summer of $1998 / 99$. This led to the layer $\left(\gamma^{n} \sim 27.5-27.6 \mathrm{~kg} \mathrm{~m}^{-3}\right)$ below the base of that year's Winter Water becoming anomalously warm, saline, $\mathrm{O}_{2}$ poor, and $\mathrm{Si}$ rich (Fig. 9), because it lay beyond the density horizon of wintertime convective mixing in 1998. The increase in $\theta$ and reduction in $\gamma^{n}$ that the Winter Water experienced that year were likely associated with the strong northerly winds (Fig. 10) and reduced sea ice cover that prevailed at that time (Fig. 14), following the arguments presented above.

To understand why these changes led to a temporary shutdown of AAIW formation in the southeast PacificDrake Passage region, we first consider how subduction of Winter Water is driven in a stationary state of the circulation. As reviewed recently by Olbers et al. (2004), the upwelling of upper CDW and downwelling of AAIW, which constitute the upper cell of the Southern Ocean overturning, can be portrayed as a residual circulation arising from the incomplete cancellation between a wind-driven Ekman overturning and an opposing eddy-induced cell. The wind-driven Ekman overturning consists of upwelling south of the PF, equatorward flow in the upper-ocean Ekman layer, downwelling north of the PF, and poleward flow in the deep ocean below the level of topographic barriers. Thus, it acts to tilt the ACC isopycnals. The regional manifestation of the dipole of near-surface Ekman upwelling and downwelling in the southern and northern ACC is shown in Fig. 10c, in which the time-mean Ekman vertical velocity is diagnosed over the 1978-2006 period.

In turn, the eddy-induced overturning is associated with baroclinic instability of the ACC frontal jets and, accordingly, acts to flatten isopycnals. This involves upwelling on the equatorward side of the front, southward flow at the surface, downwelling on the front's poleward flank, and northward flow below a certain depth. The level in the vertical at which the direction of 
a)
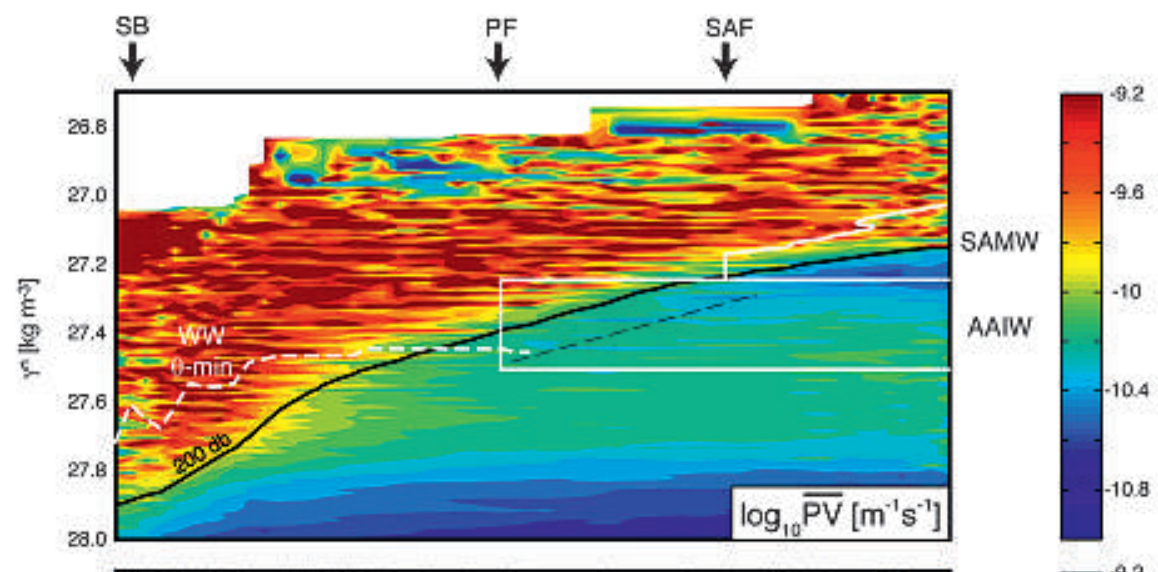

b)
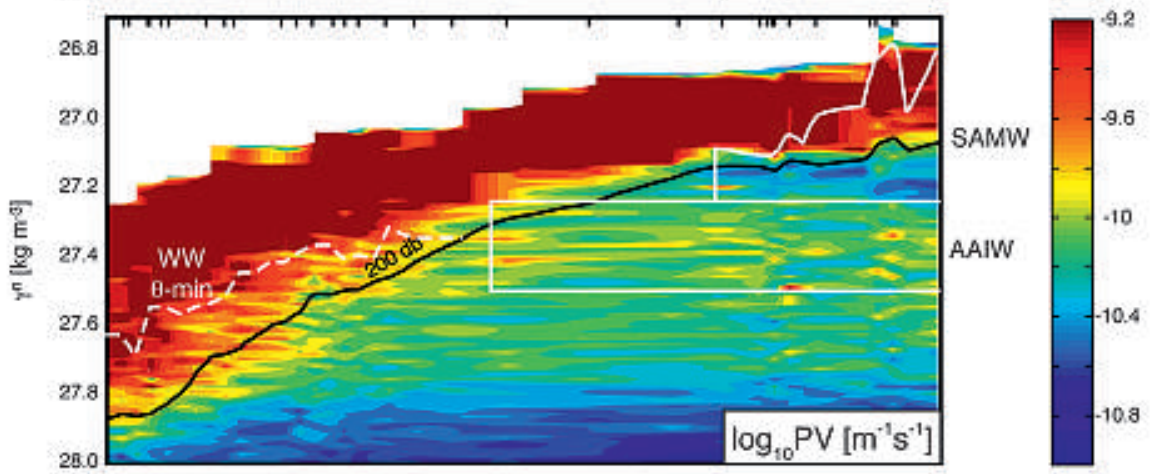

c)

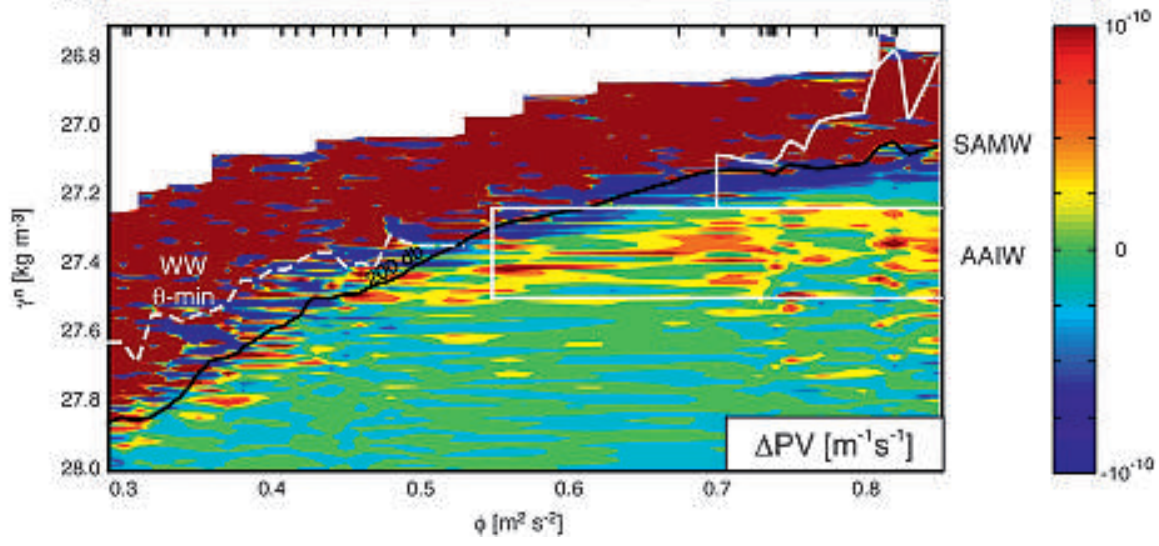

FIG. 16. Distributions of the (a) common logarithm of the time-mean (averaged over all 24 sections) PV across the Drake Passage, (b) common logarithm of the PV measured during the WOCE SR1W transect in March 1999 (Table 1), and (c) PV anomaly (i.e., with the time-mean PV subtracted) at the time. The dashed black line in (a) denotes a band of low PV associated with the winter mixed layer in the vicinity of the PF [see section $4 \mathrm{~b}(1)$ ]. The $p=200$-dbar contour (which typically lies at the base of the winter mixed layer south of the PF) in (a) the time mean and (b),(c) 1999 is shown in black, with the corresponding $\theta$ minimum of the Winter Water indicated by the white dashed line. The regions of $\varphi-\gamma^{n}$ space used in our analysis of SAMW and AAIW (see section 3) are delimited by the closed white lines. Station positions in 1999 are denoted by tick marks on the upper axis of (b) and (c). The SAF, PF, and SB are marked by arrows at the top of (a).

the eddy-driven flow reverses from southward to northward was investigated by Naveira Garabato et al. (2001), who reasoned that the eddy-driven flow on any given isopycnal must be directed up the cross-front PV (i.e., potential vorticity magnitude) gradient along that isopycnal. An illustration of their key finding is provided by Fig. 16a, which shows the mean distribution of PV as a function of $\varphi$ and $\gamma^{n}$ in the Drake Passage, averaged over all sections. Relatively high values of PV characterize the summer mixed layer, as well as much of 
the AAIW density range and lighter classes of upper CDW south of the PF. In contrast, low values of PV occur near the base of the SAMW equatorward of the SAF, throughout the densest classes of upper CDW and, more subtly, along a band connecting the southern edge of the SAMW minimum $\left(\varphi \approx 0.7 \mathrm{~m}^{2} \mathrm{~s}^{-2}\right.$ and $\gamma^{n} \approx$ $27.25 \mathrm{~kg} \mathrm{~m}^{-3}$ ) with the point at which the lower boundary of AAIW intersects the $\operatorname{PF}\left(\varphi \approx 0.55 \mathrm{~m}^{2} \mathrm{~s}^{-2}\right.$ and $\gamma^{n} \approx$ $27.5 \mathrm{~kg} \mathrm{~m}^{-3}$ ) following the dashed line in Fig. 16a. This band denotes the presence of a weak pycnostad associated with the winter mixed layer in the vicinity of the $\mathrm{PF}$, and its crossing of density surfaces is attributable to uniform wintertime atmospheric forcing and mixed layer depths across a frontal region of steep isopycnals (Naveira Garabato et al. 2001). Because of the existence of this band of slightly reduced PV values, the $27.25<$ $\gamma^{n}<27.5 \mathrm{~kg} \mathrm{~m}^{-3}$ range north of the PF must host an equatorward eddy-driven flow up the isopycnal PV gradient. This flow is reinforced by the northward Ekman drift in areas where those isopycnals penetrate the Ekman layer. Because the $27.25<\gamma^{n}<27.5 \mathrm{~kg} \mathrm{~m}^{-3}$ range coincides approximately with that of winter water and AAIW, the Winter Water subduction-AAIWventilation process can thus be understood as the combined outcome of an equatorward eddy-driven flow along the plunging isopycnals of the PF and, to a lesser extent, the wind-driven Ekman downwelling prevailing north of that front.

Using the above description as a benchmark, we next investigate how the extreme atmospheric forcing of 1998 led to a transitory change in the mode of upperocean overturning circulation across the PF region. As discussed in section $4 \mathrm{a}(1)$, the constructive interference of strongly positive SAM and negative ENSO forcings caused a very large eastward wind stress anomaly of $0.05-0.1 \mathrm{~N} \mathrm{~m}^{-2}$ to occur in the mid- to late winter of 1998, centered to the north of the SAF in the southeast Pacific and Drake Passage (Fig. 10b). A pronounced negative anomaly in wind stress curl, implying an Ekman upwelling rate of $\sim 0.5 \times 10^{-6}$ to $1 \times 10^{-6} \mathrm{~m} \mathrm{~s}^{-1}$, developed in association with and somewhat to the south of this feature, straddling the climatological position of the SAF and PF (Fig. 10d). The intensity of the upwelling anomaly was 2-4 times greater than the timemean rate of Ekman downwelling found in the area and comparable to estimates of the eddy-induced rate of Winter Water subduction at the PF (Naveira Garabato et al. 2001), suggesting that the anomalous wind forcing contributed to the transient arrest of AAIW ventilation in 1998/99. This was not, however, the only factor.

To illustrate this point, Figs. 16b,c display the distributions of the PV and the PV anomaly in the Drake Passage in March 1999. It can be seen that the extraor- dinary forcing of 1998 resulted in the production of a substantial $\left(\sim 10^{-10} \mathrm{~m}^{-1} \mathrm{~s}^{-1}\right)$ negative PV anomaly in the $27.1<\gamma^{n}<27.2 \mathrm{~kg} \mathrm{~m}^{-3}$ class north of the SAF and a corresponding positive anomaly beneath, in the $27.2<$ $\gamma^{n}<27.5 \mathrm{~kg} \mathrm{~m}^{-3}$ range. This redistribution of $\mathrm{PV}$ is a manifestation of the SAMW lightening and thickening and concurrent AAIW thinning apparent in Fig. 9. A further pair of negative and positive PV anomalies is seen extending diagonally from near the base of the SAMW at the SAF to $\gamma^{n} \sim 27.6 \mathrm{~kg} \mathrm{~m}^{-3}$ south of the PF, roughly following the $200-\mathrm{dbar}$ isobar. This feature reflects the formation of a light variety of Winter Water in 1998 and the associated compression of isopycnals at the base of that year's winter mixed layer. Significantly, the combination of these perturbations to the PV field of the upper ACC flattened the isopycnal PV gradient in the Winter Water-AAIW density class (cf. Figs. 16a,b) and must thereby have reduced the extent to which eddy-induced downwelling counteracted the Ekman upwelling anomaly [for a more comprehensive description of the relationship between the residual circulation and the PV distribution on isopycnal surfaces, see Marshall and Radko (2003)]. Therefore, we surmise that the shutdown of AAIW formation in 1998/99 was the consequence of both a prominent wintertime anomaly in Ekman upwelling and a weakening of eddy-induced downwelling associated with the destruction of isopycnal PV gradients by a primarily wind-driven reorganization of upper-ocean water masses.

Our observations of AAIW properties (Fig. 4) indicate that a full recovery from the forcing anomaly did not occur for at least two years by late 2000. The increased baroclinicity in the uppermost $\sim 800 \mathrm{~m}$ of much of the Drake Passage during 1998/99 and the compatibility of the observed recovery period with theoretical considerations of baroclinic adjustment time scales in the ACC (Olbers and Lettmann 2007) suggest that an enhancement of baroclinic instability must have been implicated in the recovery. However, we note, as above, that whereas the time-mean PV field in Fig. 16a exhibits a reversal of the isopycnal PV gradient with depth (a necessary condition for the onset of the instability; see, e.g., Pedlosky 1996), this reversal is not present in the perturbed PV distribution of 1998/99 (Fig. 16b). At that time, PV in the AAIW class north of the PF reached its highest values on record. We conjecture that AAIW formation may have been resumed shortly after the winter of 1999, when a more typical (more saline and denser than in 1998) Winter Water was formed west of the Antarctic Peninsula (Figs. 12, 14) that reestablished the diagonal band of slightly reduced PV seen in that density class in the time-mean field (Fig. 16a). Combined with the unusually high PV in the AAIW range 
farther north, the reemergence of this band must have set up a marked reversal of the isopycnal PV gradient with depth, leading to a period of intense baroclinic instability and eddy-induced flow that must have restored the pre-1998 mode of circulation. In accord with this hypothesis, Meredith and Hogg (2006) reported a transient increase in the eddy kinetic energy of the ACC core in 2000/01 (i.e., 2-3 yr after the extreme wind forcing event of 1998) that was unprecedented in the altimetric (i.e., post-1992) record. Their observation that this enhancement of eddy activity was common along the path of the ACC suggests that the Drake Passage upperocean processes discussed here may have occurred more widely across the Southern Ocean at the time.

\section{b. Interdecadal variability}

\section{1) Subantarctic Mode Water}

The interdecadal variability experienced by the SAMW flowing through the Drake Passage displays some of the broad features of the decadal-scale changes observed previously in the region of influence of the southeast Pacific-southwest Atlantic variety of the water mass. For example, Sprintall (2008) recently reported that the Drake Passage water column in the 200-700-m depth range to the north of the PF has experienced a warming trend of $\sim 0.01^{\circ} \mathrm{C} \mathrm{yr}^{-1}$ since 1970 that is comparable to our measured change in SAMW $\theta$ prior to the 1990s (Fig. 6), although the subsequent compatibility of these two metrics of change is questionable. In turn, Schneider et al. (2005) described a net freshening of the SAMW in the eastern subtropical South Pacific - which is known to be sourced from the Drake Passage region (Hanawa and Talley 2001) - between 1992 and 2003 that is coherent with the decadal-scale decrease in SAMW salinity in the passage after 1989 (Figs. 3, 6). Finally, Curry et al. (2003) provide evidence of a net post-1960s freshening [by $O(0.05)$ ] of the SAMW in the subtropical South Atlantic, which is also sourced from the Drake Passage. This freshening is similar in magnitude to the net SAMW salinity decrease documented in our Drake Passage time series (Figs. 3, 6). However, the presence of a pronounced $\sim 30$-yr oscillation in the characteristics of SAMW in the passage cautions that this correspondence may be fortuitous and raises questions about the driving mechanisms (and even the degree of genuineness) of the long-term SAMW property "trends" seen in the subtropics.

Although resolving these important climatic issues across the Southern Hemisphere oceans is beyond the sole reach of this work, we believe that the Drake Passage time series presented here can shed new light on the problem within a regional context. The key to our discussion is the relative timing of decadal variations in SAMW characteristics and the decadal evolution of the major climatic modes influencing the midlatitude South Pacific (Fig. 3). In addition to ENSO and the SAM, we examine the variability of the IPO, a fluctuation in SST and atmospheric circulation centered over the Pacific Ocean and characterized by a $15-30-y r$ periodicity (see Parker et al. 2007 and references therein). Whereas the IPO and ENSO patterns exhibit some similarities, such as a common reinforcement by positive feedbacks in the tropical atmosphere-ocean system, a comparable amplification of SST variability in the eastern tropical Pacific, and an equivalent modulation of the position of the SPCZ, a range of differences also exist. Unlike ENSO, the IPO pattern is approximately symmetric around the equator and displays equatorial and extratropical SST anomalies that are of similar magnitude. Further, its variability is characterized by a substantially longer (multidecadal) time scale than that of ENSO, which is most pronounced on interannual periods. As a result, the IPO is the leading driver of meridional displacements of the SPCZ on interdecadal time scales (Folland et al. 2002) and prevails over the low-frequency modulation of ENSO variance in shaping the decadal evolution of Pacific Ocean SST (Parker et al. 2007). For this reason, we omit consideration of the ENSO index in the context of our discussion of the interdecadal variability in SAMW. Note, however, that the physical nature of the IPO is still a matter of debate, and that the possibility of its being a manifestation of stochastic variability of ENSO projected onto interdecadal time scales cannot yet be discounted (Newman et al. 2003).

Although the limited length of our time series precludes the establishment of a statistical link between the IPO and the SAMW properties in the southeast PacificDrake Passage region, simple inspection of the two records suggests the existence of a connection. In the 1970s, warming and salinification of SAMW occurred in parallel to an increase in the IPO index, whereas post1990 SAMW cooling and freshening were accompanied by a tendency toward a negative IPO state. We view this emerging relationship as an interdecadal analog to the driving of interannual variability in SAMW properties by ENSO. As shown by Folland et al. (2002) and Parker et al. (2007), among others, a decadal-scale increase (decrease) in the IPO index is associated with surface warming (cooling) around the SAMW formation area of the southeast Pacific-Drake Passage and with a northeastward (southwestward) migration of the SPCZ that is conducive to a positive (negative) anomaly in wintermean evaporation in the region. Recall that interannualscale correspondences of the same sign were described for ENSO in section $4 a(1)$. 
If the previously inferred dominance of air-sea turbulent heat fluxes and precipitation in forcing year-toyear $\theta$ and $S$ variations in SAMW holds on interdecadal periods, changing the thermohaline properties of SAMW at the observed rates of $\sim 0.3^{\circ} \mathrm{C}$ and $\sim 0.05$ decade $^{-1}$ would entail plausibly small decadal-mean air-sea turbulent heat flux and net evaporation anomalies of $Q_{\text {anom }} \approx 1.5 \mathrm{~W} \mathrm{~m}^{-2}$ and $F_{\text {anom }} \approx 1.8 \times 10^{-9}$ $\mathrm{m} \mathrm{s}^{-1} \approx 0.06 \mathrm{~m} \mathrm{yr}^{-1}$ in the ventilation region. Forcing the same changes with perturbed Ekman fluxes of heat and freshwater would in turn require a decadal-mean zonal wind stress anomaly of $\tau_{\text {anom }}^{x} \approx 0.006 \mathrm{~N} \mathrm{~m}^{-2}$ (for $\theta)$ and $\tau_{\text {anom }}^{x} \approx 0.015 \mathrm{~N} \mathrm{~m}^{-2}$ (for $S$ ) in the limit of AASW properties in the Ekman layer having remained unchanged. It is significant that an increase in decadalmean zonal wind stress of comparable magnitude ( $\sim 0.005 \mathrm{~N} \mathrm{~m}^{-2}$ according to both the ERA-40 and NCEP-NCAR reanalyses) has occurred between the 1970s and the post-1990 period across the South Pacific, associated with a positive trend of the SAM (Fig. 3, bottom). On this basis, we suggest that this trend may have led to a gradual intensification of the Ekman supply of AASW to the SAMW formation region since the start of our record and that this may have contributed nontrivially to the SAMW cooling and freshening observed after 1990. It appears likely that this increased Ekman contribution may underlie the asymmetry between the warming and salinifying tendency of the 1970s and the somewhat more pronounced post-1990 cooling and freshening trend (Fig. 3), which culminated in the formation of the freshest $(S \sim 34.12$; cf. $S \sim 34.16-34.21$ in the 1970s and $S \sim 34.20$ in the early 1990s; see Fig. 3) and lightest $\left(\gamma^{n}<27.18 \mathrm{~kg} \mathrm{~m}^{-3}\right.$; cf. $\gamma^{n}<27.21-27.26$ $\mathrm{kg} \mathrm{m}^{-3}$ in the $1970 \mathrm{~s}$ and $\gamma^{n}<27.22 \mathrm{~kg} \mathrm{~m}^{-3}$ in the early 1990s; see Fig. 6) regional SAMW on record.

Thus, we conclude that interdecadal SAMW variability in the Drake Passage since the late 1960s has been primarily forced by changes in the state of the IPO and, to a lesser extent, the SAM.

\section{2) ANTARCTIC INTERMEdiate WATER}

The decadal freshening (by as much as 0.05 ; Figs. 4,13 ) undergone by the AAIW flowing through the Drake Passage in the last four decades is seemingly coherent with the decadal variability detected across the South Atlantic subtropical gyre, the AAIW of which is primarily renewed from the passage (e.g., You 2002). Thus, the magnitude and timing of changes in the Drake Passage suggest that they may have brought about the post-1960s freshening (by at least $\sim 0.02$ ) of AAIW observed to have occurred in the South Atlantic subtropics (Curry et al. 2003). The freshening of AAIW in the passage can be traced to a concurrent and somewhat more ample $(\sim 0.1)$ decrease in the salinity of the Winter Water of the Bellingshausen Sea (Fig. 12), which has been shown to ventilate the AAIW density class at the PF [section $4 \mathrm{a}(2)$ ]. The existence of an oceanic teleconnection between the upper layers of the Bellingshausen Sea and the subtropical South Atlantic thermocline has also been highlighted in coupled climate models (Saenko et al. 2003; Hickey and Weaver 2004).

We next seek to identify the causes of the interdecadal Winter Water freshening that preceded the decrease in Drake Passage AAIW salinity. Accounting for a freshening of no less than $0.05-0.1$ in $\sim 25 \mathrm{yr}$ (Fig. 12) in terms of a net precipitation change in the Bellingshausen Sea-southern Drake Passage region would require a plausibly small increase of at least $F_{\text {anom }}$ $\sim 5 \times 10^{-10} \mathrm{~m} \mathrm{~s}^{-1}$. Decadal-scale increases in atmospheric moisture flux convergence of this approximate magnitude have, in fact, been detected at the western edge of the Antarctic Peninsula since the 1950s, occurring in association with intensifying northerly winds possibly forced by the interdecadal positive trend of the SAM, although this remains to be verified (Turner et al. 2005; van den Broeke et al. 2006; Miles et al. 2008; Thomas et al. 2008; see also Fig. 14). In turn, explaining the same freshening through an increase in the winddriven Ekman transport of freshwater from the Bellingshausen Sea to the PF in the Drake Passage would necessitate a zonal wind stress anomaly of $\tau_{\text {anom }}^{x} \sim 0.01$ $\mathrm{N} \mathrm{m}^{-2}$ in the limit of source Winter Water properties in the Ekman layer having remained unchanged (using $L_{y}$ $\sim 550 \mathrm{~km}$ as the meridional distance between the center of the Winter Water source region and the PF, $S_{f} \approx 34.0$ as the Winter Water salinity just south of the PF, and $S_{\mathrm{Ek}} \approx 33.9$ as a characteristic Winter Water salinity in the Bellingshausen Sea). The occurrence of such a strengthening of the zonal winds between the 1970s and the turn of the century is not supported by the ERA-40 or NCEP-NCAR reanalyses, which suggest that a weakening took place instead as the positive trend of the SAM focused the regional wind field into an increasingly more cyclonic pattern.

Aside from the increase in regional precipitation, a further factor likely provided a first-order contribution to the freshening of the Winter Water-ventilating AAIW: the interdecadal retreat of the winter sea ice edge in the Bellingshausen Sea. This retreat is thought to have been driven by the strengthening of northerly winds in the region and the associated warming of the western Antarctic Peninsula, one of most rapid on earth in the last five decades (Turner et al. 2005). As advanced by Meredith and King (2005), the decline in the winter sea ice extent of the Bellingshausen Sea over recent decades led to a marked salinification of the regional 
summer mixed layer between the mid-1950s and the late 1990s. Using a mixed layer model coupled to an ice-production model, they showed that the observed weakening of the annual sea ice cycle must result in a progressive freshening of the Winter Water, because less brine rejection occurs in winter, and a salinification of the summer mixed layer, because less sea ice melts in the summer.

We can estimate the decadal-scale Winter Water freshening associated with the diminished annual sea ice cycle from the summer observations of Meredith and King (2005). These suggest that the upper $\sim 50 \mathrm{~m}\left(h_{s}\right)$ of the Bellingshausen Sea in summer experienced a salinification trend $\partial S_{s} / \partial t \approx 0.007 \mathrm{yr}^{-1}$. This summer freshwater deficit must correspond to an approximately equal wintertime freshwater gain distributed over a winter mixed layer of thickness $h_{m} \approx 150 \mathrm{~m}$. The resulting change in Winter Water salinity is $\partial S_{s} / \partial t h_{s} h_{m}^{-1}$ $\Delta t \approx 0.08$, where $\Delta t$ is taken as $36 \mathrm{yr}$ (i.e., the length of our time series). Although this wintertime freshening will be partly offset by the reduced sea ice volume melting in spring, Meredith and King (2005) showed that a considerable fraction of this spring melt ends up in the summer mixed layer rather than in the Winter Water. Thus, we contend that the Winter Water freshening associated with the interdecadal retreat of the winter sea ice field west of the Antarctic Peninsula is an important contributor to the freshening of the AAIW in the Drake Passage over the last four decades.

We thus conclude that the freshening of AAIW in the Drake Passage (and, by extension, in the subtropical South Atlantic) in recent decades was likely caused by a reduction in the salinity of the Winter Water in the Bellingshausen Sea brought about by increased precipitation and a retreat of the winter sea ice edge. These variations in regional precipitation and sea ice conditions were forced, at least in part, by an interdecadal intensification of the northerly winds to the west of the Antarctic Peninsula that may be associated (although this remains to be substantiated) with the marked positive trend experienced by the SAM since the 1960s. As pointed out by several authors (Meredith and King 2005), the wind-induced climate change in the area was likely amplified by a positive feedback between sea ice extent, upper-ocean stratification, and air temperature, of which the Winter Water freshening reported here is a by-product. Thus, a wind-driven rise of air temperature and reduction of sea ice production in wintertime will lead, through a decrease in spring melting, to a warming and salinification of the summer mixed layer. These upper-ocean changes will precondition sea ice formation to be weak the following winter and will promote a further rise of winter air temperature, thereby reinforcing the initial reduction in sea ice extent. All in all, it is thought that the ranking of the western Antarctic Peninsula as one of the regions of most rapid recent climate change on earth (e.g., Turner et al. 2005) is attributable to the unusual meridional projection of (not least SAM related) atmospheric variability (e.g., van den Broeke and van Lipzig 2004) and the exceptional positive feedback processes characterizing the region.

On this basis, we suggest that the freshening of AAIW in the Drake Passage and the South Atlantic in recent decades is likely to be a consequence of extreme regional climate change in the Bellingshausen Sea.

\section{Summary and conclusions}

A time series of physical and biogeochemical properties of SAMW and AAIW in the Drake Passage between 1969 and 2005 has been constructed using 24 transects of measurements across the passage. Analysis of the time series reveals that both water masses experienced substantial variability on interannual to interdecadal time scales, including several features that challenge the present state of knowledge on Southern Ocean mode and intermediate water formation and circulation.

The SAMW flowing through the Drake Passage is formed by winter overturning on the equatorward flank of the ACC, in a large region of deep winter mixed layers spanning quasi-zonally over $2000 \mathrm{~km}$ across the southeast Pacific and the passage itself. Its interannual variability consists of $\theta, S$, pressure, and density changes of $0.1^{\circ}-0.4^{\circ} \mathrm{C}, 0.01-0.04,30-200 \mathrm{dbar}$, and $0.01-0.02$ $\mathrm{kg} \mathrm{m}^{-3}$, respectively, with positive (negative) $\theta$ and $S$ anomalies generally covarying with layer-mean shoaling, thinning, and lightening (deepening, thickening, and densification). These changes are primarily driven by variations in wintertime air-sea turbulent heat fluxes and net evaporation modulated by ENSO and, to a lesser extent, the SAM, with the forcing occurring both locally and remotely via oceanic advection of upperocean property anomalies from the central South Pacific. A prominent exception to the usual convectiondriven overturning of SAMW in the southeast PacificDrake Passage took place in 1998, when strong wind forcing associated with constructive interference between ENSO and the SAM triggered a transitory shift to an Ekman-dominated mode of ventilation.

Despite of their spatial proximity, the AAIW in the Drake Passage has a very different source than that of the SAMW, because it is ventilated by the northward subduction at the PF of the Winter Water originating in the winter mixed layer of the Bellingshausen Sea. Similarly to SAMW, AAIW exhibits interannual $\theta, S$, pressure, and density changes of $0.1-0.3^{\circ} \mathrm{C}, 0.01-0.04$, 
10-100 dbar, and $O\left(0.04 \mathrm{~kg} \mathrm{~m}^{-3}\right)$, respectively, but positive (negative) $\theta$ and $S$ anomalies now covary with layer-mean deepening, thinning, and lightening (shoaling, thickening, and densification). These changes are primarily driven by variability in Winter Water properties resulting from fluctuations in wintertime air-sea turbulent heat fluxes and spring sea ice melting, both of which depend strongly on the intensity of meridional winds to the west of the Antarctic Peninsula. As for SAMW, ENSO dominates the forcing of interannual variations in AAIW properties, with the SAM exerting a significant influence too. Coupled with the transitory shift in the mode of SAMW ventilation, an outstanding 1-2-yr shutdown of AAIW formation was initiated in the winter of 1998, possibly driven by a prominent anomaly in Ekman upwelling and a weakening of eddyinduced downwelling associated with a wind-forced reorganization of upper-ocean water masses. Full recovery from this shutdown did not occur for at least $2 \mathrm{yr}$, and was brought about by an enhancement of baroclinic instability associated with the upper ocean's relaxation to its pre-1998 state. Overall, our observations highlight the central role that upper-ocean processes play in the ACC baroclinic adjustment and the response of the Southern Ocean overturning to changes in atmospheric forcing, a circumstance that is as yet unrecognized in numerical investigations of transient ACC states (e.g., Hallberg and Gnanadesikan 2006; Meredith and Hogg 2006; Olbers and Lettmann 2007).

Contrary to expectations based on a variety of previous observations that were mostly obtained at subtropical latitudes, the interdecadal evolutions of SAMW and AAIW in the Drake Passage are both distinct and driven by rather different processes. SAMW warmed by $\sim 0.3^{\circ} \mathrm{C}$ and salinified by $\sim 0.04$ during the 1970 s, with little change in density, whereas it experienced the reverse $\theta$ and $S$ trends between 1990 and 2005, resulting in a marked lightening of $\sim 0.06 \mathrm{~kg} \mathrm{~m}^{-3}$. The coldest, freshest, and lightest regional SAMW on record was observed at the end of our time series. In contrast, AAIW underwent a net freshening of $\sim 0.05$ between the 1970s and the turn of the century, with little detectable decadal-scale change in $\theta$ and density. Although the reversing changes in SAMW were chiefly forced by a $\sim 30$-yr oscillation in regional air-sea turbulent heat fluxes and precipitation associated with the IPO, with a SAM-driven intensification of the Ekman supply of AASW from the south contributing significantly too, the freshening of AAIW was linked to the extreme climate change that occurred to the west of the Antarctic Peninsula in recent decades. There, a freshening of the Winter Water ventilating AAIW was brought about by increased precipitation and a retreat of the winter sea ice edge, which were forced by an interdecadal trend in meridional wind stress (possibly related to a concurrent positive tendency in the SAM) and regional positive feedbacks in the air-sea-ice coupled climate system.

We note that these interdecadal thermohaline changes experienced by the SAMW and AAIW flowing through the Drake Passage represent a significant $[O(5 \%)]$ perturbation to the mean oceanic heat and freshwater divergences in the South Atlantic. Thus, if the volume transports of SAMW and AAIW [around 10 and $20 \mathrm{~Sv}$ $\left(1 \mathrm{~Sv}=10^{6} \mathrm{~m}^{3} \mathrm{~s}^{-1}\right)$, respectively; Naveira Garabato et al. 2003] through the passage are assumed constant over recent decades, the aforementioned oscillation in the $\theta$ and $S$ of SAMW and accompanying AAIW freshening must have resulted in fluctuations in the heat and freshwater transports of $O(0.02 \mathrm{PW})$ and $O(0.5 \times$ $\left.10^{6} \mathrm{~kg} \mathrm{~s}^{-1}\right)$; that is, on the order of a few percent of the mean oceanic heat and freshwater divergences in the South Atlantic south of $40^{\circ} \mathrm{S}\left[\sim 0.5 \mathrm{PW}\right.$ and $O\left(10^{7}\right.$ $\mathrm{kg} \mathrm{s}^{-1}$ ); see, e.g., Sloyan and Rintoul 2001; Ganachaud and Wunsch 2003].

Despite the limited spatial scope of the observations analyzed here, our findings on the variability of the SAMW and AAIW flowing through the Drake Passage contribute some significant insights on the present consensus on how the mode and intermediate waters of the Southern Hemisphere have evolved over recent decades (Bindoff et al. 2007). These authors indicate that a circumpolar warming and freshening of SAMW and AAIW has occurred over at least the last five decades and highlight the consistency of this pattern with the global atmospheric warming and acceleration of the atmospheric hydrological cycle (implicating widespread increased precipitation at high latitudes) that characterize many model projections of climate change in rising greenhouse gas scenarios. Whereas our results are not necessarily inconsistent with this broad picture, our conclusion that interdecadal variations of SAMW and AAIW in the Drake Passage have been markedly nonmonotonic and primarily driven by fluctuations or trends in the major modes of hemispheric climate variability (the SAM, the IPO, and ENSO) must have either of two major implications for the present consensus.

First, it may be taken to imply that the control exerted by the major climatic modes on the properties of the SAMW and AAIW in the Drake Passage (and, by extension, the SAMW in the subtropical southeast Pacific and the SAMW and AAIW in the subtropical South Atlantic) is exceptionally strong, leading to local changes in these mode and intermediate waters being essentially decoupled from SAMW and AAIW variations in other 
sectors of the Southern Ocean. This possibility stems from the SAM, ENSO, and the IPO having rather distinct manifestations in the mode and intermediate water formation areas of the southeast Pacific (e.g., the SAM exhibits a pronounced departure from zonality there, ENSO and the IPO have comparatively strong SST and precipitation footprints in the region, and unique positive feedbacks in the coupled climate system are at work in the Bellingshausen Sea; see section 4b). Second, if the changes measured in the Drake Passage are an integral part of the hemispheric-scale pattern of coherent interdecadal variations in SAMW and AAIW highlighted by the IPCC Fourth Assessment Report (a scenario that is not inconsistent with the available observations; see, e.g., Bindoff et al. 2007), our findings imply that the major modes of climate variability may play a key role in driving those changes and call for an assessment of the circumpolar footprints of the SAM, ENSO, and the IPO on water mass formation.

Regardless of which interpretation is adopted, it appears that anthropogenic influences (if any existed) on the SAMW and AAIW flowing through the Drake Passage in recent decades must have been largely indirect (i.e., mediated by the major modes of climate variability). Evidence in support of this notion is abundant in the case of the SAM, whose interdecadal tendency toward a more positive state since at least the 1960s has been repeatedly linked to stratospheric ozone losses and greenhouse gas increases (see, e.g., Arblaster and Meehl 2006 and references therein). As argued above, this tendency is likely to have contributed nontrivially to the cooling and freshening of SAMW observed in the Drake Passage after the 1980s and may have been at the origin of the regional climate change off the west Antarctic Peninsula that led to the interdecadal AAIW freshening measured in the passage since the 1970s. Thus, we conjecture that the existence of a SAMmediated anthropogenic fingerprint in the evolution of SAMW and AAIW in the Drake Passage over the last four decades is probable.

Acknowledgments. This study would not have been possible without the effort of many people at sea and ashore to collect, calibrate, and process the Drake Passage section measurements. The U.K. Natural Environment Research Council (NERC) funded 12 of the section occupations used in this work through Research Grant GR3/11654 and several core-strategic research programs at the National Oceanography Centre, Southampton and the British Antarctic Survey. It also supported ACNG through a NERC Advanced Research Fellowship (NE/ C517633/1). LJ was supported by the University of East Anglia through a Ph.D. studentship. Argo profile data were made available by the International Argo Project. We are grateful to Sheldon Bacon, Elaine McDonagh, Mike Meredith, Kurt Polzin, Ric Williams, and Adam Williams for helpful discussions and to David Parker and Andrew Colman for providing the IPO index data of Parker et al. (2007). Nathan Bindoff and two anonymous reviewers contributed valuable feedback on an earlier draft of the article. The Scientific Committee on Antarctic Research sponsored this work through its scientific research program on "Antarctica and the Global Climate System."

\section{APPENDIX}

\section{Error Analysis}

Our analysis of uncertainties in the measurements follows closely that of Williams et al. (2006 and references therein). Each observation is ascribed an uncertainty that is the sum under quadrature of three different terms: a systematic error, a standard error, and a sampling error. For potential temperature $(\theta)$, both the systematic and standard errors are $0.002^{\circ} \mathrm{C}$ for bottle transects and $0.001^{\circ} \mathrm{C}$ for the CTD sections. The sampling error is primarily a result of undersampling in the vertical and horizontal directions and affects bottle measurements especially. We estimate this term as a function of pressure $(p)$ and station spacing by subsampling the CTD section with the tightest station spacing (WOCE SR1b in December 1997-January 1998; see Table 1) with a grid mimicking bottle or relatively coarse CTD sampling and examining the biases introduced by our gridding procedure. For bottle measurements, the result is a function that decreases from $\sim 0.1^{\circ} \mathrm{C}$ near the surface to $\sim 0.01^{\circ} \mathrm{C}$ in the abyss. For salinity $(S)$, the systematic error is 0.003 for bottle measurements and 0.002 for CTD measurements. The standard error is 0.003 for bottle transects and 0.001 for CTD sections. The sampling error, estimated as for $\theta$, decreases from $\sim 0.02$ in the upper ocean to 0.002 at great depth. An analogous characterization of the uncertainty in dissolved oxygen $\left(\mathrm{O}_{2}\right)$ measurements yields systematic, standard, and sampling (below the mixed layer) errors of 3,1-2, and $\sim 3 \mu \mathrm{mol} \mathrm{kg}{ }^{-1}$, respectively. Dissolved silicate ( $\mathrm{Si}$ ) has systematic errors of $\sim 2 \mu \mathrm{mol} \mathrm{kg}^{-1}$ and standard errors of $1-2 \mu \mathrm{mol} \mathrm{kg}$. . Its sampling error cannot be quantified with confidence. Two additional error terms (a temporal and a spatial bias) are estimated for $\theta$ and $S$ with the Argo dataset. We find no appreciable intra-annual variation in the properties of SAMW and AAIW in the Drake Passage other than the modification of SAMW characteristics by winter 
convection in the region. However, we measure a small spatial bias in both water masses, which we estimate separately for each density surface by fitting a linear spatial trend to the distribution of Argo $\theta$ (and $S$ ) measurements on that isopycnal as a function of alongpassage distance. These biases amount to $\sim 0.05^{\circ} \mathrm{C}$ and $\sim 0.003$ in SAMW and $\sim 0.02^{\circ} \mathrm{C}$ and $\sim 0.002$ in AAIW.

\section{REFERENCES}

Aoki, S., N. L. Bindoff, and J. A. Church, 2005: Interdecadal water mass changes in the Southern Ocean between $30^{\circ} \mathrm{E}$ and $160^{\circ} \mathrm{E}$. Geophys. Res. Lett., 32, L07607, doi:10.1029/2004GL022220.

—_, M. Hariyama, H. Mitsudera, H. Sasaki, and Y. Sasai, 2007: Formation regions of Subantarctic Mode Water detected by OFES and Argo profiling floats. Geophys. Res. Lett., 34, L10606, doi:10.1029/2007GL029828.

Arbic, B. K., and W. B. Owens, 2001: Climatic warming of Atlantic Intermediate Waters. J. Climate, 14, 4091-4108.

Arblaster, J. M., and G. A. Meehl, 2006: Contributions of external forcings to southern annular mode trends. J. Climate, 19, 2896-2905.

Bindoff, N. L., and J. A. Church, 1992: Warming of the water column in the southwest Pacific Ocean. Nature, 357, 59-62.

_ , and T. J. McDougall, 1994: Diagnosing climate change and ocean ventilation using hydrographic data. J. Phys. Oceanogr., 24, 1137-1152.

— , and —, 2000: Decadal changes along an Indian Ocean section at $32^{\circ} \mathrm{S}$ and their interpretation. J. Phys. Oceanogr., 30, $1207-1222$.

—_, and Coauthors, 2007: Observations: Oceanic climate change and sea level. Climate Change 2007: The Physical Science Basis, S. Solomon et al., Eds., Cambridge University Press, 385-432.

Bryden, H. L., E. L. McDonagh, and B. A. King, 2003: Changes in ocean water mass properties: Oscillations or trends? Science, 300, 2086-2088.

Curry, R., R. R. Dickson, and I. Yashayaev, 2003: A change in the fresh water balance of the Atlantic over the past four decades. Nature, 426, 826-829.

Curtis, S., and R. F. Adler, 2003: Evolution of El Niñoprecipitation relationships from satellites and gauges J. Geophys. Res., 108, 4153, doi:10.1029/2002JD002690.

Ferrari, R., and F. Paparella, 2003: Compensation and alignment of thermohaline gradients in the ocean mixed layer. J. Phys. Oceanogr., 33, 2214-2223.

Fogt, R. L., and D. H. Bromwich, 2006: Decadal variability of the ENSO teleconnection to the high-latitude South Pacific governed by coupling with the southern annular mode. J. Climate, 19, 979-997.

Folland, C. K., J. A. Renwick, M. J. Salinger, and A. B. Mullan, 2002: Relative influences of the Interdecadal Pacific Oscillation and ENSO on the South Pacific Convergence Zone. Geophys. Res. Lett., 29, 1643, doi:10.1029/2001GL014201.

Fyfe, J. C., O. A. Saenko, K. Zickfeld, M. Eby, and A. Weaver, 2007: The role of poleward-intensifying winds on Southern Ocean warming. J. Climate, 20, 5391-5400.

Ganachaud, A., and C. Wunsch, 2003: Large-scale ocean heat and freshwater transports during the World Ocean Circulation Experiment. J. Climate, 16, 696-705.

Gille, S. T., 2002: Warming of the Southern Ocean since the 1950s. Science, 295, 1275-1277.
- 2008: Decadal-scale temperature trends in the Southern Hemisphere ocean. J. Climate, 21, 4749-4765.

Gloersen, P., and W. B. White, 2001: Reestablishing the circumpolar wave in sea ice around Antarctica from one winter to the next. J. Geophys. Res., 106, 4391-4395.

Grist, J. P., and S. A. Josey, 2003: Inverse analysis adjustment of the SOC air-sea flux climatology using ocean heat transport constraints. J. Climate, 16, 3274-3295.

Hallberg, R., and A. Gnanadesikan, 2006: The role of eddies in determining the structure and response of the wind-driven Southern Hemisphere overturning: Results from the Modeling Eddies in the Southern Ocean (MESO) project. J. Phys. Oceanogr., 36, 2232-2252.

Hanawa, K., and L. D. Talley, 2001: Mode waters. Ocean Circulation and Climate, G. Siedler, J. Church, and J. Gould, Eds., International Geophysical Series, Vol. 77, Academic Press, 373-386.

Harangozo, S. A., 2006: Atmospheric circulation impacts on winter maximum sea ice extent in the west Antarctic Peninsula region (1979-2001). Geophys. Res. Lett., 33, L02502, doi:10.1029/ 2005 GL024978.

Hickey, H., and A. J. Weaver, 2004: The Southern Ocean as a source region for tropical Atlantic variability. J. Climate, 17, 3960-3972.

Jackett, D. R., and T. J. McDougall, 1997: A neutral density variable for the world's oceans. J. Phys. Oceanogr., 27, 237-263.

Johnson, G. C., and A. H. Orsi, 1997: Southwest Pacific Ocean water-mass changes between 1968/69 and 1990/91. J. Climate, 10, 306-316.

Josey, S. A., E. C. Kent, and P. K. Taylor, 1998: The Southampton Oceanography Centre (SOC) ocean-atmosphere heat, momentum and freshwater flux atlas. Southampton Oceanography Centre Rep. 6, 30 pp.

Kalnay, E., and Coauthors, 1996: The NCEP/NCAR 40-Year Reanalysis Project. Bull. Amer. Meteor. Soc., 77, 437-471.

Lefebvre, W., H. Goosse, R. Timmermann, and T. Fichefet, 2004: Influence of the Southern Annular Mode on the sea iceocean system. J. Geophys. Res., 109, C09005, doi:10.1029/ 2004JC002403.

Marshall, G. J., 2003: Trends in the southern annular mode from observations and reanalyses. J. Climate, 16, 4134-4143.

Marshall, J., and T. Radko, 2003: Residual-mean solutions for the Antarctic Circumpolar Current and its associated overturning circulation. J. Phys. Oceanogr., 33, 2341-2354.

McCartney, M. S., 1977: Subantarctic mode water. A Voyage of Discovery: George Deacon 70th Anniversary Volume, M. Angel, Ed., Pergamon, 103-119.

McDonagh, E. L., H. L. Bryden, B. A. King, R. J. Sanders, S. A. Cunningham, and R. Marsh, 2005: Decadal changes in the south Indian Ocean thermocline. J. Climate, 18, 1575-1590.

Meredith, M. P., and J. C. King, 2005: Rapid climate change in the ocean west of the Antarctic Peninsula during the second half of the 20th century. Geophys. Res. Lett., 32, L19604, doi:10.1029/2005GL024042.

, and A. M. Hogg, 2006: Circumpolar response of Southern Ocean eddy activity to a change in the Southern Annular Mode. Geophys. Res. Lett., 33, L16608, doi:10.1029/ 2006GL026499.

, K. E. Grose, E. L. McDonagh, K. J. Heywood, R. D. Frew, and P. F. Dennis, 1999: Distribution of oxygen isotopes in the water masses of Drake Passage and the South Atlantic. $J$. Geophys. Res., 104, 20 949-20962. 
— E. J. Murphy, E. J. Hawker, J. C. King, and M. I. Wallace, 2008: On the interannual variability of ocean temperatures around South Georgia, Southern Ocean: Forcing by El Niño/ Southern Oscillation and the southern annular mode. DeepSea Res. II, 55, 2007-2022.

Miles, G. M., G. J. Marshall, J. R. McConnell, and A. J. Aristarain, 2008: Recent accumulation variability and change on the Antarctic Peninsula from the ERA-40 reanalysis. Int. J. Climatol., 28, 1409-1422.

Naveira Garabato, A. C., J. T. Allen, H. Leach, V. H. Strass, and R. T. Pollard, 2001: Mesoscale subduction at the Antarctic Polar Front driven by baroclinic instability. J. Phys. Oceanogr., 31, 2087-2107.

- D. P. Stevens, and K. J. Heywood, 2003: Water mass conversion, fluxes, and mixing in the Scotia Sea diagnosed by an inverse model. J. Phys. Oceanogr., 33, 2565-2587.

Newman, M., G. P. Compo, and M. A. Alexander, 2003: ENSOforced variability of the Pacific decadal oscillation. J. Climate, 16, 3853-3857.

Olbers, D., and K. Lettmann, 2007: Barotropic and baroclinic processes in the transport variability of the Antarctic Circumpolar Current. Ocean Dyn., 57, 559-578.

— D. Dorowski, C. Völker, and J.-O. Wolff, 2004: The dynamical balance, transport and circulation of the Antarctic Circumpolar Current. Antarct. Sci., 16, 439-470.

Orsi, A. H., T. Whitworth III, and W. D. Nowlin Jr., 1995: On the meridional extent and fronts of the Antarctic Circumpolar Current. Deep-Sea Res., 42, 641-673.

Parker, D., C. Folland, A. Scaife, J. Knight, A. Colman, P. Baines, and B. Dong, 2007: Decadal to multidecadal variability and the climate change background. J. Geophys. Res., 112, D18115, doi:10.1029/2007JD008411.

Pedlosky, J., 1996: Ocean Circulation Theory. Springer-Verlag, $453 \mathrm{pp}$.

Piola, A. R., and A. Gordon, 1989: Intermediate waters in the southwest South Atlantic. Deep-Sea Res., 36, 1-16.

Reynolds, R. W., N. A. Rayner, T. M. Smith, D. C. Stokes, and W. Wang, 2002: An improved in situ and satellite SST analysis for climate. J. Climate, 15, 1609-1625.

Rintoul, S. R., and M. H. England, 2002: Ekman transport dominates local air-sea fluxes in driving variability of Subantarctic Mode Water. J. Phys. Oceanogr., 32, 1308-1321.

— C. W. Hughes, and D. Olbers, 2001: The Antarctic Circumpolar Current system. Ocean Circulation and Climate, G. Siedler, J. Church, and J. Gould, Eds., International Geophysical Series, Vol. 77, Academic Press, 271-302.

Saenko, O. A., and A. J. Weaver, 2001: Importance of wind-driven sea ice motion for the formation of Antarctic Intermediate Water in a global climate model. Geophys. Res. Lett., 28, $4147-4150$.

_ - _ and M. H. England, 2003: A region of enhanced northward Antarctic Intermediate Water transport in a coupled climate model. J. Phys. Oceanogr., 33, 1528-1535.

Santoso, A., and M. H. England, 2004: Antarctic Intermediate Water circulation and variability in a coupled climate model. J. Phys. Oceanogr., 34, 2160-2179.

Schneider, W., M. Fukasawa, H. Uchida, T. Kawano, I. Kaneko, and R. Fuenzalida, 2005: Observed property changes in eastern South Pacific Antarctic Intermediate Water. Geophys. Res. Lett., 32, L14602, doi:10.1029/2005GL022801.
Sloyan, B. M., and S. R. Rintoul, 2001: The Southern Ocean limb of the global deep overturning circulation. J. Phys. Oceanogr., 31, 143-173.

Smith, C. A., and P. D. Sardeshmukh, 2000: The effect of ENSO on the intraseasonal variance of surface temperatures in winter. Int. J. Climatol., 20, 1543-1557.

Sprintall, J., 2008: Long-term trends and interannual variability of temperature in Drake Passage. Prog. Oceanogr., 77, 316-330.

Stark, S., R. A. Wood, and H. T. Banks, 2006: Reevaluating the causes of observed changes in Indian Ocean water masses. J. Climate, 19, 4075-4086.

Talley, L. D., 1996: Antarctic Intermediate Water in the South Atlantic. The South Atlantic: Present and Past Circulation, G. Wefer et al., Eds., Springer-Verlag, 219-238.

Thomas, E. R., G. J. Marshall, and J. R. McConnell, 2008: A doubling in snow accumulation in the western Antarctic Peninsula since 1850. Geophys. Res. Lett., 35, L01706, doi:10.1029/2007GL032529.

Thomas, L. N., 2005: Destruction of potential vorticity by winds. J. Phys. Oceanogr., 35, 2457-2466.

Timmerman, R., A. P. Worby, H. Goosse, and T. Fichefet, 2004: Utilizing the ASPeCt sea ice thickness data set to validate a global coupled sea ice-ocean model. J. Geophys. Res., 109, C07017, doi:10.1029/2003JC002242.

Trenberth, K. E., and J. M. Caron, 2000: The Southern Oscillation revisited: Sea level pressures, surface temperatures, and precipitation. J. Climate, 13, 4358-4365.

Turner, J., 2004: Review: The El Niño-Southern Oscillation and Antarctica. Int. J. Climatol., 24, 1-31.

- and Coauthors, 2005: Antarctic climate change during the last 50 years. Int. J. Climatol., 25, 279-294.

van den Broeke, M. R., and N. P. M. van Lipzig, 2004: Changes in Antarctic temperature, wind and precipitation in response to the Antarctic Oscillation. Ann. Glaciol., 39, 119-126.

_- W. J. van de Berg, and E. van Meijgaard, 2006: Snowfall in coastal West Antarctica much greater than previously assumed. Geophys. Res. Lett., 33, L02505, doi:10.1029/ 2005 GL025239.

Verdy, A., J. Marshall, and A. Czaja, 2006: Sea surface temperature variability along the path of the Antarctic Circumpolar Current. J. Phys. Oceanogr., 36, 1317-1331.

Visbeck, M., 2009: A station-based southern annular mode index from 1884 to 2005. J. Climate, 22, 940-950.

Watanabe, T., M. Ikeda, and M. Wakatsuchi, 2004: Thermohaline effects of the seasonal sea ice cover in the Sea of Okhotsk. J. Geophys. Res., 109, C09S02, doi:10.1029/2003JC001905.

Williams, A., S. Bacon, and S. Cunningham, 2006: Variability of the Lower Circumpolar Deep Water in Drake Passage 1926-2004. Geophys. Res. Lett., 33, L03603, doi:10.1029/ 2005 GL024226.

Wong, A. P. S., N. L. Bindoff, and J. Church, 1999: Large-scale freshening of intermediate waters in the Pacific and Indian Oceans. Nature, 400, 440-443.

- - — , and — 2001: Freshwater and heat changes in the North and South Pacific Oceans between the 1960s and 1985-94. J. Climate, 14, 1613-1633.

You, Y., 2002: Quantitative estimate of Antarctic Intermediate Water contributions from the Drake Passage and southwest Indian Ocean to the South Atlantic. J. Geophys. Res., 107, 3031, doi:10.1029/2001JC000880. 